\title{
The emergence of care robotics - A patent and publication analysis
}

\author{
Moritz Goeldner ${ }^{1 *}$, Cornelius Herstatt ${ }^{1}$ and Frank Tietze ${ }^{2}$
}

1) Institute for Technology and Innovation Management, Hamburg University of Technology, Germany

2) Institute for Manufacturing, University of Cambridge, UK

\begin{abstract}
Care robots are a means to support elderly people affected by physical or mental handicaps to remain as autonomous as possible or regain already lost autonomy (e.g. running stairs). They also support care-takers when working with handicapped. We review the emergence of care robotics and particularly offer answers to two research questions: Which organizations and individuals in which countries have been and are active in research and development? How has research and development emerged with regard to activity focus, intensity levels and cooperation?
\end{abstract}

The analysis rests on PATSTAT patent and ISI Web of Science publication data. Bibliographic and network analyses are conducted on country, organization (i.e. universities and firms) and individual levels. We find that care robotics research and development activities have constantly increased since the late 1970 s. Today Japanese universities and firms are the most active players, while in early stages US and European organizations pioneered care robotics research. Starting from six disjunctive small networks, several highly interconnected care robotics research networks have evolved. However, most cooperation clusters are still found within the same country. Only few international hubs emerged. Among them are two Japanese organizations (ATR, AIST) and Carnegie Mellon University, US.

Keywords: Technology emergence; Care robotics; Bibliometric analysis; Network analysis

* Corresponding author: Tel: +49 40428783775

E-Mail addresses: moritz.goeldner@tuhh.de,c.herstatt@tuhh.de,frank.tietze@eng.cam.ac.uk 


\section{INTRODUCTION}

The term care robotics as used in this paper encompasses all machines that operate partly or fully autonomously performing care-related activities for people with physical and/or mental handicaps. These handicaps are related to age and/or health-related restrictions. Among others care robots are meant to simplify tasks of the daily life for aged and/or otherwise handicapped people. Such highly specialized machines shall increase the quality of life of their users by giving them more autonomy [1], by protecting them and/or by performing certain tasks with a certain quality standard (for example serving medication, drinks or food).

Different types of care robotics have already been developed. The Care-O-Bot is a first example [2]. Already in its third generation this autonomously operating device is being developed by the Fraunhofer Institute for Manufacturing Engineering and Automation (IPA), Germany. The third generation has a grappler in the back and a tray in the front. It can detect obstacles, move around and avoid them. Having the appearance of a robotic "butler" this machine fulfills a repertoire of transporting functions. For instance, it delivers water to residents in senior homes or hospitals. The care robot identifies, approaches and talks to its "customers". It documents its work and allows doctors and care takers to analysis that data (e.g. to verify whether patients have consumed sufficient water over a day).

A very different type of a care robot is Paro, a robotic baby seal that has been developed for patients suffering from dementia. Developed by Takanori Shibata at the National Institute of Advanced Industrial Science and Technology (AIST) in Japan, Paro is equipped with two microphones and several sensors to detect light, sound and other environmental stimuli. On an emotional level Paro interacts with patients through movements of its fins and eyes [3]. Research about the effects of Paro use in therapeutic treatments shows that it has a stimulating as well as a calming effect on the patients, facilitating discussions and interactions among dementia patients and influences the 
affectionate behavior of those positively when turned on [3]. Paro is the first commercially available care robot.

Both examples (Care-O-Bot and Paro) are examples for autonomously operating machines which directly interact with users. However, care robots being developed today are not only meant to directly support elderly or handicapped. Instead, some solutions explicitly address the needs of caretakers in their daily work. In many countries we observe labor shortages in the health care sectors due to increasing costs and/or shrinking budgets [4]. This often results in higher workloads for individual caretakers in hospitals or retirement homes. Besides this issue certain care-related tasks cause physical problems and long-term health issues for caretakers, for example from frequently moving heavy patients. Consequently, the number of staff on sick leave in this profession today is higher than average [5]. Care robots may help by improving the working conditions and thereby will presumably positively affect the health and work satisfaction of caretakers.

An example for this case is RIBA, the carrying-robot. RIBA is developed by RIKEN in Japan, a major national research institute. Riba is operated by a nurse while carrying a patient on the basis of touchsensors which are activated by the guiding nurse. Each of Riba's arms has six joints, each driven by six motors, which operate in pairs to enable combined bending and twisting motions. With the support of Riba caretakers can safely move persons up to $80 \mathrm{~kg}$. Riba identifies human faces using visual data from stereo cameras, and can localize the position of a speaker's voice with onboard microphones.

Care robots are receiving growing interest in public and industry and a number of factors speak in their favor. For example, many industrialized countries like Japan or Germany today observe accelerated aging of their populations. The rapidly growing percentage of people aged 65 or older on the one hand, the shrinking birth rates on the other will have major impacts on both, the society and the economy of each of the affected countries. Coupled with the decreasing size of the working-age population, we can expect a serious bottleneck in the area of elderly care in the upcoming decades. Apart from that, the current elderly generation has more money to spend compared to earlier 
generations and invests in products and services designed to improve their lives $[1,6]$ and prolong their autonomy, which is appears to be a major concern of elderly people [7]. Products and services, including robots, will likely enable people to (re-) gain autonomy and to live a "normal life". Furthermore, the health-care costs for caring for elderly people are constantly increasing. Currently the expenses for nursing one person at home are in the range between $\$ 30.000$ and $\$ 60.000$ per annum. These expenses have more than doubled in the last decade [8].

Consequently researchers and engineers in public as well as private organizations in different parts of the world are involved in projects targeted to develop solutions corresponding to the various needs of different potential user groups. However, comparing care robots to other automatized appliances such as "household robots", there are a number of differences that cause demand for dedicated care-robot research. Care robots incorporate diverse and often complex functions when interacting with humans. For example care robots may have to maneuver stairs in senior homes and robotic devices that pick up and move immobile people have to be much more reliable compared to a robotic vacuum cleaner. Further, care robots have to conform to stringent safety regulations complying with different national legal requirements. Care robots are in more or less close physical contact with individuals or even socially interacting with people. This so-called Human-RobotInteraction requires interdisciplinary research combining knowledge from areas such as robotics, social and cognitive sciences, medicine and neuroscience [9]. This aspect again adds additional complexity regarding safety, ethical and regulatory issues $[10,11]$.

Due to the expected growth for care-robots in the future and the need for dedicated care-robot research this paper seeks to provide a comprehensive evaluation of the field contributing answers to the following two questions: 
1. Which organizations and individuals in which countries have been and are active in related research and development?

2. How has related research and development emerged with regard to activity focus, intensity levels and cooperation?

The remainder of the paper is divided into four sections. Following the brief introduction to care robotics, we have presented our research questions. The next section introduces our methodological approach. Results of bibliographic and network analyses are presented in the third section. The fourth section discusses the results reflecting upon both research questions and suggests for further research.

\section{MethodologicAl APPROACH}

Patent (e.g. [12-14]) and publication data (e.g. $[15,16])$ is widely used to map the emergence of technologies. We applied a multi-source approach combining two complementary datasets similar to Daim et al. (2006), Kumaresan and Miyazaki (1999), and Järvenpää et al. (2011) [17-19]. We collected and analyzed priority patent application and scientific publication data. The patent data was extracted from the Worldwide Patent Statistical Database PATSTAT (version 09/2010). Scientific publication data was obtained from ISI Web of Science.

Both patent and publication data was extracted using the same search strategy. Search keywords were developed in an iterative procedure aiming to maximize recall and precision [20]. In each step, keywords were defined for data extraction. The resulting data was screened for more effective keywords. The process was repeated until saturation was achieved. The most effective keywords were validated by an expert in the care robotic field and resulted into a combination of two positivekeyword-lists and one negative-list (Table 1). From both positive-lists at least one keyword has to be included in the publications' or patents' title, abstract, or keywords. The negative-list comprises 
keywords that are not allowed to occur in any of them in order to exclude unsuited patents and publications, for example industrial or surgical robots.

\section{INSERT TABLE 1 ABOUT HERE}

Scientific publication data was collected from ISI Web of Science applying the search strategy in October 2010. The initial data extraction resulted in 2435 publications. After a manual screening for content fit 904 publications were manually removed. The huge majority could easily be detected as unrelated to care robotics (e.g. space- or underwater robots, robot assistants in logistics, editorials and publications with main focus on social sciences). The few cases with uncertain relations to care robots were carefully examined among the authors. Furthermore, all publications with missing information (e.g. missing author or contact address) were deleted, resulting in a final data set of 1535 publications. Patent data was collected in two steps during December 2010 and January 2011. Firstly, we ran the search strategy in PATSTAT that resulted in 2636 patent applications. PATSTAT however lacked abstracts for Japanese patent applications, wherefore Japanese patent data was specifically extracted from freepatentsonline.com. This led to 1847 results. All patent were manually checked to validate the relevance of each patent for this project. This was necessary, because patent titles and abstracts tend to be written on a general level, often hardly reflecting the specific content of a patent [21]. In a second step, the results from both databases were merged and utility models were excluded. This list was reduced to contain only priority patents (i.e. the patent of a patent family that has the earliest filing date [22]). The final data set includes 564 priority patent applications. For both, scientific publications and priority patent applications, the spelling of names and organizations was manually homogenized if different spellings were detected.

For analyzing the datasets, besides common descriptive measures we used citation data. Furthermore, for the dataset of publications only we applied a social network analysis (SNA). ${ }^{1}$ SNAs have been proven to be an efficient method to identify central researchers, institutions, publications,

\footnotetext{
${ }^{1}$ For analyzing the patent data a SNA could have been hardly applied. Only $6 \%$ of all patent applications were filed by multiple applicants, resulting in just 28 patent applications, in which collaboration could be assumed.
} 
journals and research clusters (i.e. hidden colleges) as well as their activity developments over time $[15,16,23,24]$. In line with its common purpose we applied an SNA for identifying, measuring and displaying relations between organizations collaboratively active in the care robotics field.

For our analysis three common SNA measures are applied. The Nodal Degree is defined as the number of lines that are connected to a node. The density of a graph describes the network as a whole and considers the amount of lines and nodes within the network. The more lines exist within a network related to the amount of nodes, the higher is a network's density [25]. The centrality of a node in a graph is a measure to describe how important a certain node is compared to other nodes. From different centrality types (degree centrality, closeness centrality, betweenness centrality) we apply the degree centrality measure because it is the most common centrality measure in nondirectional relations [25]. The analysis was conducted using the software ORA, developed at Carnegie Mellon University (USA). For the SNA only publications were considered with multiple authors in general and particularly those that were published by authors from two or more different organizations. Thus, the dataset for the SNA includes 712 publications that were published by 756 organizations.

\section{DATA ANALYSIS AND FINDINGS}

This section is divided into two parts. First, the results of descriptive analyses of both datasets are presented comparing the numbers of scientific publications and priority patent applications on the country, organizational and individual level. Afterwards, the results of the social network analysis are presented for the dataset comprising only publications. 


\subsection{DESCRIPTIVE RESULTS}

The number of patent applications and publications increased steadily since first patents applications appeared in the late 1970 s (see Figure 1 ). ${ }^{2}$ These initial patent applications covered primarily technical details, especially dealing with robot hands and arms, but also provided concepts on general robot programming. Until 1990, only one to four patent applications were filed annually. Initial publications appeared in 1983. Publications from the early 1980s cover opportunities for possible application areas (e.g. "the personal bench-top robot - a low-cost, friendly assistant" [26], "service robotics" [27] or "robots in health-care - looking a robot in the eye" [28].

\section{INSERT PICTURE 1 ABOUT HERE}

In the early 1990's patent applications and publications were continuously filed, respectively published. A first notable, but small increase in patenting activity took place in 1992. Until 1996 patenting remained on a small scale and fairly constant at around 20 annual applications. Until 1996, patents concentrated on robot's hands and arms as well as autonomous navigation. Similar to patenting activities, the number of publications rose after 1991 from very few to about 20 per annum. During this time, first experiments with mobile robots for disabled persons were conducted, for instance "towards a practical mobile robotic aid system for people with severe physicaldisabilities" [29] or an "introduction to the special issue on robotics for health-care" [30]. The number of publications started to exceed the annual patent applications after 1993. At the end of the 20th century, the number of annual publications exceeded 50, addressing various specific topics, for example the localization of moving objects, learning robots or robots behavior in complex environments [31, 32]. Different researchers and groups started to construct prototypes and to publish results of experiments, like the "HelpMate, a service robot with experience" [33], "the service robot MOPS: First operating experiences" [34] or "a day in the life of Isaac" [35].

\footnotetext{
${ }^{2}$ The first patent application in our dataset is titled "physical training robot" (US1974 0499 194). It was filed by Jardine Industries (US) in August 1974.
} 
At the beginning of the 21th century, the overall patenting activity started to rise slightly with 30 to around 50 annual applications in 2005. Since then we witness a constant level with some variation. Patents in this era dealt with the robot's locomotion and interaction with humans. Recently, the content of patent applications shifted direction towards humanoids (e.g. facial mimics of robots, man-like moving or speaking), therapeutic issues and companionship. While the number of annual patent applications remained fairly constant, between 2002 and 2003 the number of annual publications doubled, rising to 130 in 2003. Since then the number of publications has grown constantly to about 210 in 2009. In this period scientific publications focused on more complex robot tasks, for instance "realization of tai-chi motion using a humanoid robot" [36]. Results of long-term tests are presented for example: "robot assisted activity at a health service facility for the aged for ten weeks" [37] or the reliability of robots, for example in retirement homes, as elaborated in "planning under uncertainty for reliable health care robotics" [38]. Overall, care robots related patenting activity rose by $24 \%$ on average per year from 1985 to 2010 . In the same period, worldwide patenting rose by little more than $3 \%$ annually [39].

On country level, Table 3 depicts the geographical distribution of all priority patent applications and scientific publications across four cohorts of five years each. ${ }^{3}$ Accordingly, $97 \%$ of all care robotics patent applications were first filed in five countries, $71 \%$ in Japan only ${ }^{4}$. Non-Asian countries with substantial patenting activity are the USA, Germany and France. Today, South Korea and China patent more then all European countries taken together. South Korea, China has more recently come to the scene being the second most active patenting country by the end of 2009. South Korea quadrupled its amount of patent applications in the last two cohorts whereas China's number of patent applications even grew sevenfold.

\section{INSERT TABLE 2 ABOUT HERE}

\footnotetext{
${ }^{3}$ The first cohort includes all patents applications, respectively scientific publications prior to 1974 .

${ }^{4}$ This is not due to the one-claim one-patent policy operated in Japan which was terminated in 1988. [40]
} 
Japan's number of annual patent applications developed in an opposite direction. Even though Japan had still the most applications between 2005 and 2009, its patenting activity has decreased compared to the previous cohort (2000-2004). Although the exact number of patent applications from 2009 in our dataset is incomplete due to reasons explained above, it appears not likely that Japan's "real" number of annual patent applications has substantially grown to exceed the number of the previous cohort.

The analysis of publications, based on the authors' institutional addresses, reveals a slightly different picture. In total the publications from these five countries together account for only $37 \%$ of all publications. Hence, the publication landscape is by far not that dominated by these five countries than the patenting activities. However, among the top publishing countries Japan also ranks first, but the differences to the other counties are not quite as striking as for the number of patent applications. The USA, South Korea and Germany appear also strongly active. After 1999 South Korea, after its first publication in 1994 - four years before the first Korean patent application was filed - increased its publishing activity rapidly. A similar pattern can be observed for China, which started publishing in 1999 (two years before its first patent application) and increased its activity in this field continuously. Although, overall China remains far behind the other countries on rank five.

\section{INSERT TABLE 3 ABOUT HERE}

On the organizational level the results from our analysis differ with regard to the most frequent patenting organizations and those with high publishing activity across the two datasets (see Table 3). Not surprisingly private companies dominate the patenting activities, while universities and national research institutes predominately publish publications in scientific journals. Overall the top ten patentees filed $31 \%$ of all patent applications, while the number of publications from the top ten publishing organizations accounts for $25 \%$ of the total. Among the top 10 patenting and publication organizations not any organization appears on both lists. 
Japanese organizations both substantially dominate patenting activities and scientific publications likewise. Except one Korean company, nine out of the top ten patenting organizations are from Japan. Together the Japanese organizations filed for $29 \%$ of all patent applications. One might have to note that prior to 1988 patent applications in Japan were allowed to have only one claim. Thus, the number of patent applications was automatically higher than in other countries [41]. Already the top patentee Sony has filed $5 \%$ of all applications. With regard to scientific publications, five of the top ten organizations are from Japan. Two are each from Korea and the US and one from Germany (on the last rank). The Japanese organizations published $13 \%$ of all publications.

\section{INSERT TABLE 4 ABOUT HERE}

The analysis of citation data for the publications ${ }^{5}$ of the organizations reveals (see Table 4) that only two organizations have more than 100 cumulative annual citations (Carnegie Mellon University from the US and ATR from Japan). Eight organizations have between 100 and 50 cumulative citations. Among them are three leading US universities (MIT, University of Michigan and the University of Southern California). Also one European university (Ecole Polytechnique from France) and one organization from South Korea (KAIST) are among the Top 10 ranked organizations. The first company (Sony from Japan) appears on position twelve.

\section{INSERT TABLE 5 ABOUT HERE}

The analysis of citation data for the patent applications of the organizations reveals (see Table 5) that nine of ten most frequent patenting organizations are firms, except one research organization from Germany. Five of them are from the US (one company being a joint venture of a US and a Japanese company). Three companies are from Germany and only two from Japan, among the first and second

\footnotetext{
${ }^{5}$ As a measure for citations we calculated the annual citations of each publication until 2010, when our data was collected, and the sum for each organization. By calculating average cumulative citations we account for the effect that older papers / patents have a higher probability to accumulate more citations than younger ones.
} 
ranked. Among the leading ten patentees only two multinational corporations are present, both from Japan (Sony, Honda).

\section{INSERT TABLE 6 ABOUT HERE}

A closer look at the top ten ranked individuals with regard to patenting and publication activities reveals the following picture (see Table 6). Overall the top ten patentees applied for 69 patents and published 380 publications. With $12 \%$ (10\%) of all patent applications (publications) the share of the ten top ranked individuals is unsurprisingly lower than the share of the top ten organizations ( $31 \%$, respectively 25\%). All of the most active patentees filled their patents between 1989 and 2007.

\section{INSERT TABLE 7 ABOUT HERE}

Among the top 10 individuals with the highest patenting and publishing activity, only one author appears in both lists. Ishiguro Hiroshi, who is currently employed by the intelligent robotics laboratory of Osaka University with a visiting group leader position at ATR, ranks second in patenting and fourth in publication activities. Examining the top ten ranked individuals concerning their patent activity reveals that nine of them are from Japan. Two of the top ten patentees are or were employed each by Mitsubishi, ATR, and Tech Corporation. The patentee who ranks third actually comes from a Chinese organization, surprisingly employed by the Beijing Institute of Technology, a university. As in patenting, the Japanese supremacy can also be seen in publishing, also with nine out of ten authors originating from Japan. Three of the Japanese authors are / were employed by AIST. Two authors are / were employed by the University of Tokyo or ATR. With 19 publications each, one of the two top ranked authors however is from the US, employed at the MIT.

Analyzing highly cited individual publications we find that none of the ten most cited publications is younger than 1999 (see Table 7). Also, not any author appears as contributor to multiple of the highest ten cited publications. Among the authors are seven from US universities and seven from European universities ( $3 \times \mathrm{FR}, 1 \times \mathrm{BE}, 1 \times \mathrm{IT}, 1 \times \mathrm{UK}$ ) and one author comes from a Turkish university. 
Again, among the organizations to which the authors are affiliated only one company appears coming from Japan (Sony).

\section{INSERT TABLE 8 ABOUT HERE}

Analyzing highly cited patent applications we find that the ten most cited papers have been filled between 1987 and 2006 (see Table 8). Six of the ten applicants are US firms. Two are from Germany, of which one is a research institute. Among the top ten most cited patents, only one is from a Japanese company (again Sony). None of the most highly cited patents appears to have emerged from cooperative research activities of multiple organizations.

\subsection{CARE ROBOT RESEARCH NETWORKS}

This section presents the results of a social network analysis (SNA) to determine the development of collaborative research contributing to the development of care robotics. In total (see Table 8Error! Reference source not found.) we identified 712 partnerships from joint publications and 28 partnerships from jointly applied patents (i.e. publications/patents with multiple authors/inventors from different organizations). These numbers represent $47 \%(6 \%)$ of the total number of publications (patents). All results are presented sequentially for four periods. While the second and third periods represent ten years, the first period includes all patents / publications prior to 1994 . The fourth period includes all patents / publications from 2005 to 2009.

Table 9 reveals that the number of joint publications has continuously grown over all four periods, with the largest growth rate from the second to the third period. In contrast, a continuous growth is not reflected by the number of patent cooperations that had its peak between 2000 and 2004 .

\section{INSERT TABLE 9 ABOUT HERE}


Table 10 presents data for the 23 patents that emerged from collaborative development work. The patents were filled between 1987 and 2008. The data reveals the clear dominance in Japanese firms and universities in patenting activity. The collaborations take place primarily between nationally or publicly funded partners. Unfortunately, the low number of collaborations identified from patent data hardly allows for conducting an SNA, wherefore we present only SNA results for research collaborations that were identified from publications.

\section{INSERT TABLE 10 ABOUT HERE}

\section{Period $1983-1994$}

Between 1983 and 1994 we identified six collaboration networks (see Figure 3) from the SNA that involve a total of 18 research organizations. Together only seven joint publications resulted from these six networks.

\section{INSERT FIGURE 2 ABOUT HERE}

One of two international collaborations (A) also represents the largest network involving seven universities. Four partners are from the US and three from the UK. In this cluster and also overall in this first period, Stanford University from the US had the highest centrality degree. Stanford researchers collaborated with three other US universities (Washington University, San Francisco State University and University of Berkeley, California) and three universities from the UK (Imperial College, University of Sussex and University of Brighton). The other international collaboration (B) is bilateral and involves the NASA Jet Propulsion Laboratory from the US and the Korean Electric and Telecommunication Research Institute. The four remaining networks represent national bi- or trilateral collaborations ( $2 \times$ US, $1 \times$ Australia, $1 \times$ Japan).

In this first observed period the overall and particular international cooperation level must be considered as on a small scale. Researchers primarily worked with colleagues from the same university. In the few observed collaborations it seems reasonable to assume that physical work proximity was important for selecting collaboration partners in this early phase of care robots 
development. Modern communication means (e.g. internet and e-mail) were not yet existent and travelling across continents was less common then today. Most joint scientific publications were thus published predominantly by scholars from research institutes located in close proximity of each other. Japan in this early phase did not play a major role.

Period $1995-1999$

In the second period the number of research collaborations increased compared to the previous period. In total 36 research collaborations could be observed involving researchers from 70 organizations (see Table 8). Universities dominate the partner structure, with however ten companies being actively involved in eleven collaborations.

\section{INSERT TABLE 11 ABOUT HERE}

Despite an increased number of organizations, the collaboration landscape still appears fragmented. No major international hub or cluster had yet evolved. Only 36 publications from this period are available and most cooperation activities resulted in first, joint publications. The two largest networks with five organizations ( $A, B)$ each involve both only national partners $(1 \mathrm{x}$ Japan, $1 \mathrm{x}$ Europe, more precisely UK), both including however one industrial partner (Matsushita (JP) and Integral Solution Ltd. (UK)). Four of five networks with four partners are instead international (C, D, E, $\mathrm{G})$. Four of the remaining cooperations have three partners, while the remaining 14 collaborations have only two partners, several of them however involving international partners.

\section{INSERT FIGURE 3 ABOUT HERE}

In contrast to the first period, in the second period European organizations dominate the collaboration landscape (see 


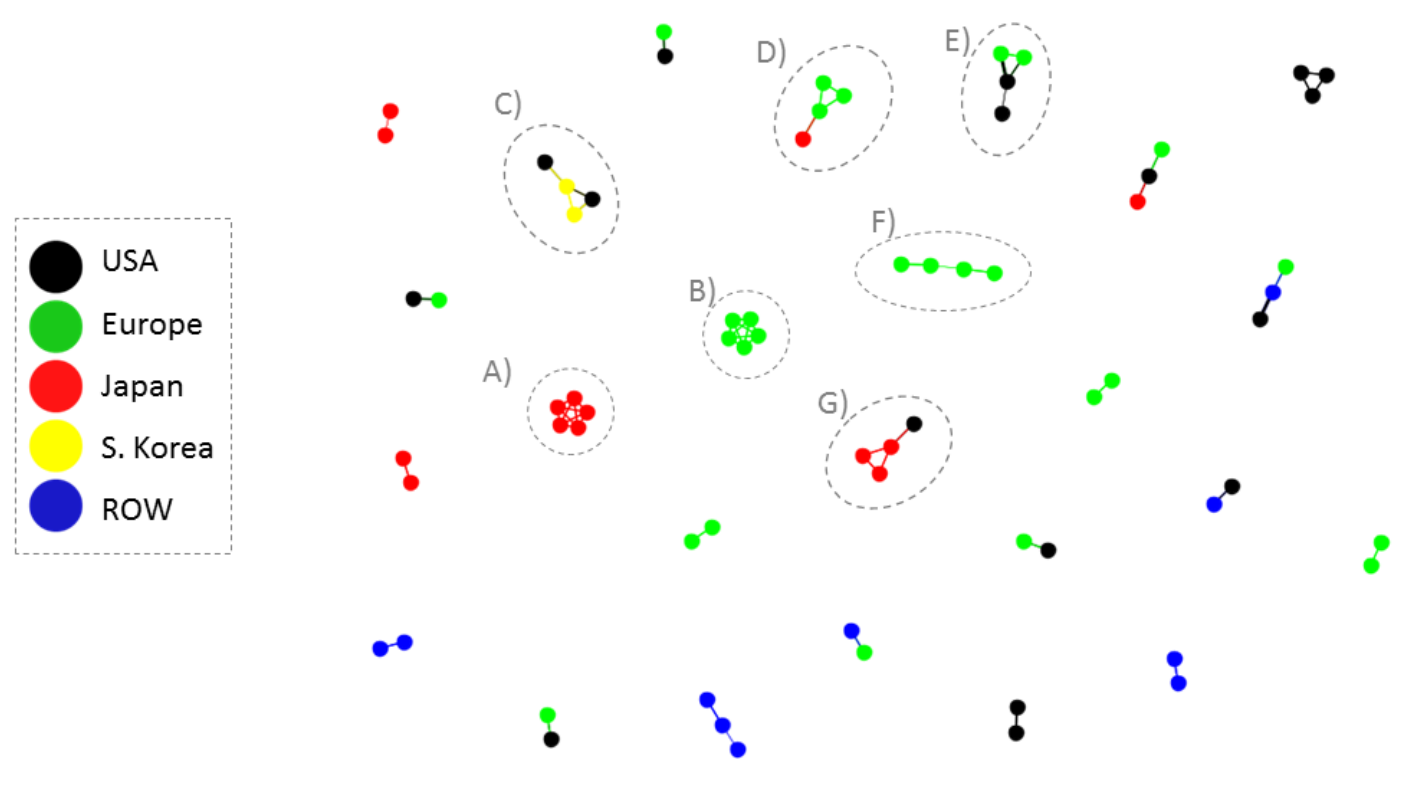

Figure 3). European organizations have one purely UK-based collaboration with five partners (B, Imperial College London, Queen Mary \& Westfield College London, Brunel University, Integral Solution Ltd as well as a UK-based research fund) and one network (F) with four partners (University Edinburgh, University of Karlsruhe, Siemens AG and Rhode \& Schwarz GmbH). This latter subnetwork is the only network that includes two companies. 17 US organizations and 12 Japanese organizations are involved in various collaborations, while - for example - five organizations collaborate in one national Japanese network already.

Universities that occur in the first and second period are Tokyo Institute of Technology, Imperial College London and University of Wollongong. However, as the total number of publications still remained on a low level, the SNA reveals not yet any organization that appears to have a central role connecting a larger number of international organizations. We thus conclude that in this second period national collaborations still dominate. Nevertheless, we observe an overall higher number of inter-national collaborations, especially between US and European organizations. But the collaboration landscape still appears to be fragmented and not any dominating network has emerged with more than four partners.

Period $2000-2004$ 
In the third period, the number of organizations that actively engage in research collaborations has grown to 285, most of them European (89), Japanese (80) and US (59) organizations (see 
Table 11Error! Reference source not found.). These include 231 universities but also 54 companies that engage in 215 joint publications.

Among the ten most central organizations, Japanese organizations now clearly dominate. Besides them two US universities are among the ten most active organizations. One of them (Carnegie Mellon University) appears to be the most important collaboration partner for others in this period, followed by two Japanese organizations (University of Tokyo and the Advanced Telecommunication Research Institute (ATR)). Only one company (Sony from Japan) appears in that list.

\section{INSERT TABLE 12 ABOUT HERE}

The SNA for this period reveals five major networks that involve more than five partners (see Figure 4). The largest network (A) with 106 organizations is largely dominated by Japanese organizations (54). In this network also 28 European organizations participate as well as 14 US organizations besides ten organizations from other countries across the world. Loosely connected to this network is another relatively large network (B) with 21 partners, dominated by US organizations. Three other networks appear from the SNA with more than five partners. One network (C) involves only eleven European organizations. Another network (D) is dominated by six organizations from South Korea involving also two Japanese organizations and one from Bulgary. The third network (E) involves three partners from South Korean and five from other countries.

\section{INSERT FIGURE 4 ABOUT HERE}

A closer look the largest network (A) reveals two sub-networks with more frequent collaborations (i.e. with more than two joint publications). The first major sub-network $\left(A_{1}\right)$ involves 16 organizations that appear more frequently. While Japanese organizations dominate with nine organizations, Carnegie Mellon University from the US seems to be the most central organization. Carnegie Mellon has six frequent partnerships with two US universities (Georgia Institute of Technology, University of Michigan), two European organizations (Jozef Stefan institute, the largest research institute in Slovenia and Ecole Polytech de France) and close contact to two important 
Japanese organizations (ATR and AIST). The second sub-network $\left(A_{2}\right)$ involves four partners only from Japan (Japan Science and Technology Agency, Kyoto University and the two companies Sony and Honda).

\section{INSERT FIGURE 5 ABOUT HERE}

For this period we can conclude that international care robotics research has reached a breakthrough. The number of collaborations has sky-rocked increasingly involving also companies, although mainly from Japan. Carnegie Mellon University from the US has established itself as the major international hub for care robotics research with close links to two major Japanese organizations (ATR, AIST) but two European organizations.

Period $2005-2009$

Compared to the previous period, in the fourth period the number of collaborations has again grown to 447 , likewise as the number of different organizations that collaborated (542). In this period, with $35 \%$ the highest share of collaborating organizations comes from European organizations (see Table 7). With $22 \%$ US organizations have the second highest share of all collaborating organizations, followed by Japanese organizations (16\%) and South Korean organizations $(9 \%)$. The high share of collaborating organizations (82\%) indicates that it has become a de facto standard to conduct research collaboratively.

Aside the geographical distribution by number of organizations, the picture differs with regard to the most central (i.e. active) organizations. Here, Japanese organizations dominate again this period. From the ten leading active organizations, seven come from Japan; among them the three leading organizations (ATR, AIST and Osaka University). From the US only Carnegie Mellon University and the University of Southern California appear within the leading ten organizations. Furthermore, one organization from South Korea (KIST, Korean Institute of Science and Technology) appears on this list.

\section{INSERT TABLE 13 ABOUT HERE}


Figure 6 presents the collaborative network structure from 2005 to 2009. Although we still observe several cooperations with two, three or four partners, a major multinational network has evolved with more than 200 collaborating organizations. Various Japanese organizations (A, B, C) can be found in the center of this network. Furthermore, a number of European (D), US-American (E) and South Korean organizations (F) formed mainly national sub-networks.

\section{INSERT FIGURE 6 ABOUT HERE}

When taking into account only collaborations with at least two joint publications, the structure as depicted in Figure 7 emerges. The analysis reveals three major sub-networks: The largest (B) is the most multinational one involving six Japanese partners, five from South Korea, two from the US, one from France and another one from Mexico. The most central organization in this network appears to be AIST from Japan. The second largest sub-network $(\mathrm{A})$ is bi-national including eleven partners from Japan and three from the US. The most central partner in this sub-network is ATR from Japan. Both sub-networks appear disconnected without any partner being active in both of them. As in the previous period, Osaka University has a major collaboration with ATR, whereas University of Tokyo rather collaborates with AIST. Besides the two major sub-networks six Japanese organizations collaborate in a purely national network (C).

\section{INSERT FIGURE 7 ABOUT HERE}

For this period we can conclude that Japanese organizations appear most active and central and also more internationally connected than in the previous periods. US organizations are closely linked to the Japanese ones. While European organizations are numerous, they appear to be fairly disconnected from the two major sub-networks. South Korean organizations on the other hand (still) collaborate predominantly with national partners, only linked to the AIST centered major subnetwork (B) through the Korean Institute of Science and Technology (KIST). On the corporate side, only two companies appear more frequently involved in research collaborations. One of them is from Japan (Sony) being only involved in national collaborations, likewise as the second company, which is 
from South Korea (Samsung). As none of the companies appear in the list of leading organizations, we can conclude that companies have decreased their interest in collaborative activities. ${ }^{6}$

\section{Summarizing $1983-2009$}

Considering the total period from 1983 to 2009, 756 organizations ( $79 \%$ of all organizations) engaged in 712 research cooperations. With an overall share of $36 \%$ European organizations dominate the collaboration landscape, followed by 167 (22\%) US and 140 (19\%) Japanese organizations (see Table 14).

\section{INSERT TABLE 14 ABOUT HERE}

The majority of the most active organizations however come not from Europe but rather from Asia. Among the leading ten organizations, seven organizations are from Japan and one from South Korean. Only two non-Asian organizations appear on this list coming from the US instead. Despite the relative high share of companies cooperating with universities (18\%), only one company (Sony) is among the most active organizations, which is from Japan. European organizations rather collaborate with only some partners, Asian organizations are much better inter-connected within the network. Japanese organizations have much international collaboration whereas South Korean organizations rather cooperate on a national level.

\section{INSERT FIGURE 8 ABOUT HERE}

Figure 9 depicts a more detailed look at the core network (i.e. only organizations with more than one joint publication) This analysis reveals 65 organizations with the largest share from Japan (48\%), followed by 13 organizations from South Korea and eight each from the US and Europe ( $3 \times$ Germany, $2 \times$ Italy, $2 \times$ France, $1 \times$ Slovenia). Five organizations from across the world also appear in this core network from China, India, Iran, Israel and Mexico.

\footnotetext{
${ }^{6}$ This issue has been identified and discussed with Japanese researchers: After a strong focus on research in this field at the beginning of the 21th century, there seems to have be disappointment about the failure of bringing no product (except toy robots) to the market [42].
} 
Among the 65 organizations, the analysis reveals an axis of six organizations that appear to be central partners in national sub-networks which also partly represent links to international sub-networks. Four of these organizations are from Japan (AIST, ATR, Kyoto University, Osaka University) and one organization comes each from the US (Carnegie Mellon University) and one is from South Korea (KIST). European organizations hardly appear to have any central role.

\section{INSERT FIGURE 9 ABOUT HERE}

The largest network emerged around ATR (Japan) with direct links to 13 partners. Among them are only two US universities (Carnegie Mellon, University of Southern California) and one European partner (Jozef Stefan Institute in Slovenia). In both sub-networks that center around Carnegie Mellon University (US) and AIST (Japan), the central organizations have direct links to nine partners. Overall, however the sub-network centered around Carnegie Mellon University appears to be the most international one with $2 / 3$ of the partners not being from the US. Carnegie Mellon is linked directly to three European organizations (University of Bonn in Germany, Jozef Stefan Institute in Slovenia and Ecole Polytechnique in France). But Carnegie Mellon University appears also to be the link between the sub-networks centered around both leading Japanese organizations, AIST and ATR. The sub-network around AIST has five Japanese partners, but AIST also cooperates with two US universities (Carnegie Mellon, Stanford), one French university (University of Toulouse) and the University of Guanajuato from Mexico.

The additional two sub-networks that center around the two Japanese universities in Osaka and Kyoto appear less international. Osaka University has direct links to eight organizations which are primarily from Japan. Osaka University only partners with one US university (Indiana University) and the Jahangirnagor University from India. Kyoto University has only direct links to Japanese organizations. Similarly appears the sub-network centered around the Korean Advanced Institute of Science and Technology. While this institute does not appear as an international hub in the axis linking the different sub-networks, it also partners directly with six national partners. 


\section{INSERT TABLE 15 ABOUT HERE}

Among all actors, we find only few companies with a high centrality. Three of the top 5 companies (see Table 14) are from Japan (Sony, Honda and Matsushita). For South Korea, we identified Samsung and LG Electric, which published care robotics research in the overall period from 1983 to 2009.

Over the full period from 1983 to 2009 we can conclude that the highest numbers of collaborating organizations come from Europe and the USA. However, Japanese organizations are most actively collaborating, although primarily nationally. While US or European organizations rather collaborate with few organizations, Japanese organizations appear to be highly interconnected with each other. Six out of the top 10 universities and three out of the top 5 companies (measured by degree centrality) are located in Japan. However, surprisingly both large Japanese research organizations ATR and AIST appear fairly disconnected, i.e. only connected through Carnegie Mellon University from the US.

\section{DISCUSSION AND CONCLUSIONS}

The purpose of the study was to develop a first, international picture on the emergence of care robotics research and development and cooperation networks. Analyzing publications and patent activities we provided this - a first and rough picture on (inter-)national, organizational and partly individual contributions since its early beginning in the 1970s. Analyzing two complementary datasets in four periods we show how collaborative activities developed over time. We explored early centers of gravity, emerging networks as well as shifting levels of activities between European, US-based and Asian actors. Our analysis so far is descriptive and looking at the two indicators and data sources we used, the overall picture resulting is still of limited granularity only. Clearly more research is needed to better understand motives, strategies and resource allocation decisions of the various actors. 
To a large extent the data extraction and cleaning was carried out manually, particularly because we had to use two separate databases for patents and publications. Although we could show that analyses based on both data can reveal valuable insights, the procedure was resource consuming and only partially recommendable for future studies. With regard to reliability and repeatability, future studies should preferably employ at least a semi-automatized data collection procedure. While we certainly recommend future studies using both patent and publication data, colleagues conducting these studies may have it easier anyway. For instance, nowadays Web of Science offers the possibility to search both in publications (e.g. social science citation index), but also to search the same time in the Derwent Innovation Index, which provides access to patent data (given that institutional access to both databases is available). Other databases, such as SciFinder-Scholar and Scopus also allow to search both in patent and publication data.

What conclusions - if any - can be drawn so far? Both the patenting and publishing activity in the field of care robotics has substantially increased since the beginning of the 1970s, with a development pattern appearing similar in both datasets. We interpret this as an increasing interest in this topic from both, industry and academia. Apart from the general desire to understand and improve technological opportunities being drivers for research and development, other factors have influenced this development. Among these the demographic development, increasing aging, a decrease in working-age population, and raising healthcare costs acted seem to play a major role.

The country being most active in care robotics with regard to patent applications and publishing is Japan. This result might not be particularly surprising, since Japan is perceived as the most active country in robotics in general. For example, in Japan the highest number of industrial robots per capita is installed and most robotic toys have their origin in Japan [43]. But this dominance was not always the case since other countries - the US and Europe - were initially much more active in the field. But the picture has changed over the last 30 years. Nowadays and besides Japan, South Korea and China have become important players in care robotics. Geographical and cultural closeness to Japan might be contributing factors for this. Influential non-Asian countries are still the US and 
Germany with few distinctive centers or hubs. Particularly Carnegie Mellon University needs to be mentioned here that (still) appears to be the most internationally active institution in care robotics research.

Our implicit assumption that patent work is primarily performed by companies and publishing primarily by research institutions including universities is supported by our data: While $72 \%$ of the patent applications involve at least one company, almost all publications are related to research institutions. We only found Sony as an example for an organization being equally active in both, publishing and patenting.

Further research on behavior of academic-industry cooperation could be performed using our datasets. The combination of patent and publication data offers various opportunities for further research, particularly when investigating how organizations incorporate knowledge developed by universities and vice versa. For that purpose, patents and publications could be evaluated contextwise for example by means of a semantic analysis.

When analyzing the titles of the patents and publications, the explicit purpose or usage of robotics in order to care for elderly or disabled has not appeared until 2005. Previously, researchers and developers mostly dealt with more generic, technical aspects of robots like its' extremities or moving and interacting with humans in a safe and reliable manner. This change of research agenda can be seen in both patents and the scientific literature. We argue that the interest in care robotics in this narrow, focused sense has only recently started. We further hypothesize that this development is closely connected to the challenges expected to come along with more and more aging people in countries like Japan, USA and Germany - the countries being most active in research and development of care robotics. This seems only consequent and we therefore expect the work on care robotic to further increase in the coming years ${ }^{7}$.

\footnotetext{
${ }^{7}$ We excluded the data of scientific publications in 2010 and 2011 in this paper for comparison reasons with the patent data - however the dataset shows a continuous growth in these two years.
} 
Although having the same trend, the levels on which publishing and patenting take place are different. Especially towards recent years, the number of scientific publications has increased to multiple times the number of patent applications. This is not surprising, because while there is only one patent for a specific invention, numerous publications can be written about it, putting it in different contexts and describing various aspects of the invention.

Over the years, the number of patent applications that Japanese companies filed remained virtually on the same level with a slightly declining trend. The amount of scientific publications instead has increased steadily. It is very likely that a reason for this is that most of the Japanese research has only in the last ten years been published in the English language making it available to the main body of researchers and making it possible to find with the search method that was employed in this study. At the same time, more companies in other countries begin to see the potential of care robotics and start to invest in this field. Especially China and South Korea show an increase in patenting activity, which contrasts the current situation in Japan. Both countries are comparably new players in this field, having started in the beginning of 2000 and the mid-1990s respectively - but they exponentially increase their numbers in both scientific publications and patent applications, giving rise to the assumption that they are quickly catching up.

Germany had almost no patenting activity until the last observed period (2005-2009), while its publishing activity has been present and increasing from the beginning. Similarly, the US has had a low but constant level of patents since the beginning, with the exception of the 1990s, while their publishing activity has the same development as the German one, only on a higher level. The general development however is an incline in both realms, indicating an increased interest in the area of care robotics - albeit so far predominantly in research rather than development.

Contrasting the growth of patenting related to care robotics with worldwide patenting statistics indicates the increased relevance of the topic. While US and European actors were among the pioneers, Japan has invested most in the field and dominates it. However, aside of Japan western 
societies are strongly affected by the demographic change. The Japanese government seems to have recognized the need for technological support systems, such as care robots. Japan may emerge as a lead market with important technological expertise in the field, while western countries may lack behind. If western governments want to avoid future dependencies to access Japanese knowledge (e.g. license payments) they should strengthen R\&D initiatives in the field. Specific R\&D programs could be initiated to facilitate cooperation with leading Japanese (and Korean) research organizations, particularly the University of Tokyo, AIST (and KAIST) and corporations, such as Sony, Honda and Toshiba (see Table 3).

Both, research institutes and industrial firms develop care robots responding to the many, expected challenges. But so far, only very few of the many initiatives have been successfully implemented in market solutions. Many barriers like technical, legal, financial and safety-related issues stand in the way and need to be resolved before we can expect care robots to appear on the market in larger quantities. Further the technology-acceptance of robots and willingness to pay by potential customers and users need to be better understood and respected.

\section{ACKNOWLEDGMENTS}

We like to thank Saskia Rehder for assisting us with the data collection for the patent analysis. 


\section{BIBLIOGRAPHY}

[1] C. Herstatt, F. Kohlbacher, P. Bauer, Silver Product Design - Product Development for older people, in: Working Paper No. 65, Institute for Technology and Innovation Management, Hamburg University of Technology, 2011.

[2] B. Graf, U. Reiser, M. Hagele, K. Mauz, P. Klein, Robotic home assistant Care-O-bot ${ }^{\circledR}$ 3-product vision and innovation platform, in: Advanced Robotics and its Social Impacts (ARSO), 2009 IEEE Workshop on, IEEE, 2009, pp. 139-144.

[3] W. Taggart, S. Turkle, C. Kidd, An interactive robot in a nursing home: Preliminary remarks, in: Towards Social Mechanisms of Android Science: A COGSCI Workshop, 2005.

[4] K. Köhler, M. Goldmann, Soziale Innovation in der Pflege - Vernetzung und Transfer im Fokus einer Zukunftsbranche, in: J. Howaldt, H. Jacobsen (Eds.) Soziale Innovation, VS Verlag für Sozialwissenschaften, Wiesbaden, 2010, pp. 253-270.

[5] T. Hackmann, Arbeitsmarkt Pflege: Bestimmung der künftigen Altenpflegekräfte unter Berücksichtigung der Berufsverweildauer, Sozialer Fortschritt, 59 (2010) 235-244.

[6] F. Kohlbacher, P. Gudorf, C. Herstatt, Silver Business in Japan: Implications of Demographic Change for Human Resource Management and Marketing, German Chamber of Commerce and Industry in Japan, (2010).

[7] M. Silverstein, A. Abramson, How Baby-Boomers in the United States Anticipate Their Aging Future: Implications for the Silver Market, in: F. Kohlbacher, C. Herstatt (Eds.) The Silver Market Phenomenon, Springer, Heidelberg, 2008, pp. 55-69.

[8] R. Barea, L.M. Bergasa, E. Lopez, M. Ocana, D. Schleicher, A. Leon, Robotic assistants for health care, in: IEEE International Conference on Robotics and Biomimetics, Bangkok, Thailand, 2009, pp. 1099-1104.

[9] A. Tapus, M.J. Mataric, B. Scassellati, The grand challenges in socially assistive robotics, IEEE Robotics and Automation Magazine, 14 (2007) 35-42.

[10] B.C. Stahl, N. McBride, K. Wakunuma, C. Flick, The empathic care robot: A prototype of responsible research and innovation, Technological Forecasting and Social Change, 84 (2014) 74-85.

[11] N. Sharkey, The ethical frontiers of robotics, Science, 322 (2008) 1800-1801.

[12] F. Tietze, E. Reul, C. Herstatt, The relation of patent ownership and firm success cases from the LCD Flat-Panel-Display industry, International Journal of Technology Intelligence and Planning, 5 (2009) 90-109.

[13] T. Jung, O. Ejermo, Demographic patterns and trends in patenting: Gender, age, and education of inventors, Technological Forecasting and Social Change, 86 (2014) 110-124.

[14] T. Schweisfurth, F. Tietze, C. Herstatt, Exploring the coevolution of design and technology, in: 18th International Product Development Management Conference, Delft, The Netherlands, 2011. 
[15] N. Shibata, Y. Kajikawa, Y. Takeda, I. Sakata, K. Matsushima, Detecting emerging research fronts in regenerative medicine by the citation network analysis of scientific publications, Technological Forecasting and Social Change, 78 (2011) 274-282.

[16] Y. Kajikawa, Y. Takeda, Citation network analysis of organic LEDs, Technological Forecasting and Social Change, 76 (2009) 1115-1123.

[17] T.U. Daim, G. Rueda, H. Martin, P. Gerdsri, Forecasting emerging technologies: Use of bibliometrics and patent analysis, Technological Forecasting and Social Change, 73 (2006) 981-1012.

[18] N. Kumaresan, K. Miyazaki, An integrated network approach to systems of innovation - the case of robotics in Japan, Research Policy, 28 (1999) 563-585.

[19] H.M. Järvenpää, S.J. Mäkinen, M. Seppänen, Patent and publishing activity sequence over a technology's life cycle, Technological Forecasting and Social Change, 78 (2011) 283-293.

[20] D. Dirnberger, A guide to efficient keyword, sequence and classification search strategies for biopharmaceutical drug-centric patent landscape searches-A human recombinant insulin patent landscape case study, World Patent Information, 33 (2011) 128-143.

[21] J.T. Butler, Patent Searching Using Commercial Databases, in: M.A. Lechter (Ed.) Successful patents and patenting for engineers and scientists, IEEE Press, New York, 1995, pp. 36-64.

[22] P. Zuniga, D. Guellec, H. Dernis, M. Khan, T. Okazaki, C. Webb, OECD Patent Statistics Manual, in, Paris: OECD Publications, 2009.

[23] A. Saka, M. Igami, Mapping modern science using co-citation analysis, in: IEEE 11th International Conference Information Visualization Zurich, 2007, pp. 453-458.

[24] É. Gauthier, S. Statistics Canada, P. Technology Redesign, I. Statistics Canada. Science, D. Electronic Information, Bibliometric analysis of scientific and technological research: A user's guide to the methodology, Science and Technology Redesign Project, Statistics Canada, 1998.

[25] S. Wasserman, K. Faust, Social network analysis: Methods and applications, Cambridge University Press, Cambridge, 2008.

[26] D.R. Ahlgren, The personal bench-top robot - a low-cost, friendly assistant, Am. Ceram. Soc. Bull., 62 (1983) 879-879.

[27] C. Meunier, Service Robotics, Annales Des Mines, 192 (1985) 107-109.

[28] P.A. Finlay, Robots in health-care - looking a robot in the eye, Chartered Mechanical Engineer, 34 (1987) 21-23.

[29] M.A. Regalbuto, T.A. Krouskop, J.B. Cheatham, Toward a practical mobile robotic aid system for people with severe physical disabilities, Journal of Rehabilitation Research and Deveopment, 29 (1992) 19-26.

[30] M. Kassler, Introduction to the special issue on robotics for health care, Robotica, 11 (1993) 493494. 
[31] G. Lawitzky, SINAS-a navigation system for service robots, Industrial Robot: An International Journal, 26 (1999) 451-455.

[32] T. Hamada, M.G. Fujie, Robotics for social safety, Advanced Robotics, 15 (2001) 383 - 387.

[33] G. Engelberger, HelpMate, a service robot with experience, Industrial Robot: An International Journal, 25 (1998) 101-104.

[34] N. Tschichold-Gürman, S.J. Vestli, G. Schweitzer, The service robot MOPS: First operating experiences, Robotics and Autonomous Systems, 34 (2001) 165-173.

[35] J. Engelberger, A day in the life of Isaac, Industrial Robot: An International Journal, 27 (2000) 176-180.

[36] T. Wama, M. Higuchi, H. Sakamoto, R. Nakatsu, Realization of tai-chi motion using a humanoid robot, in: M. Rauterberg (Ed.) Entertainment Computing - ICEC 2004, Springer, Eindhoven, The Netherlands, 2004, pp. 14-19.

[37] K. Wada, T. Shibata, T. Saito, K. Tanie, Robot assisted activity at a health service facility for the aged for ten weeks: an interim report of a long-term experiment, Proceedings of the Institution of Mechanical Engineers, Part I: Journal of Systems and Control Engineering, 220 (2006) 709-715.

[38] N. Roy, G. Gordon, S. Thrun, Planning under uncertainty for reliable health care robotics, in: S. Yuta, H. Asama, S. Thrun, E. Prassler, T. Tsubouchi (Eds.) Field and Service Robotics, Springer, Berlin, 2006, pp. 417-426.

[39] WIPO statistics database (June 2014).

[40] M. Sakakibara, L. Branstetter, Do stronger patents induce more innovation? Evidence from the 1988 Japanese patent law reforms, Rand Journal of Economics, 32 (2001) 77-100.

[41] J. Lerner, Patent policy reform and its implications, NBER Reporter: Research Summary, 6 (2003) $17-19$

[42] Y. Kusuda, The humanoid robot scene in Japan, Industrial Robot: An International Journal, 29 (2002) 412-419.

[43] C. Wagner, The Japanese way of robotic: Interacting "naturally" with robots as a national character?, in: The 18th IEEE International Symposium on Robot and Human Interactive Communication, 2009, pp. 510-515. 


\section{FIGURES}

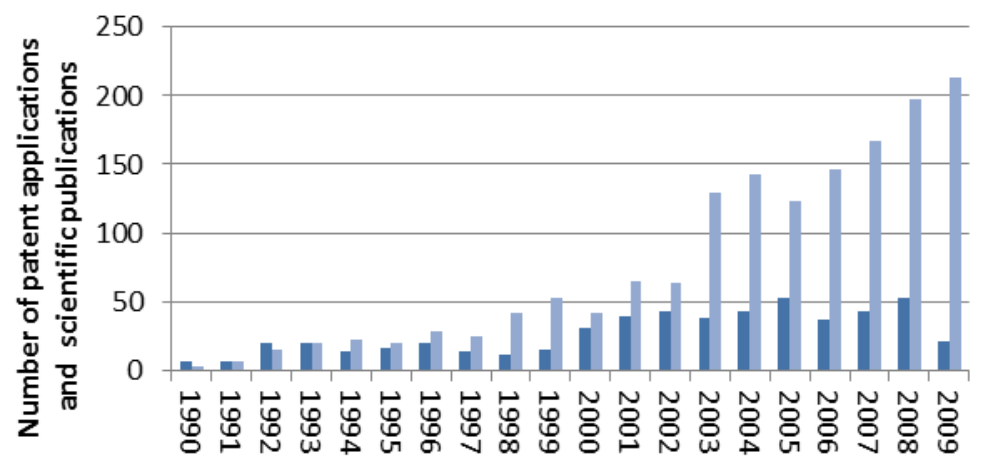

- Patent applications $\quad$ Scientific publications

Figure 1: Development of annual patent applications and publications ${ }^{8}$

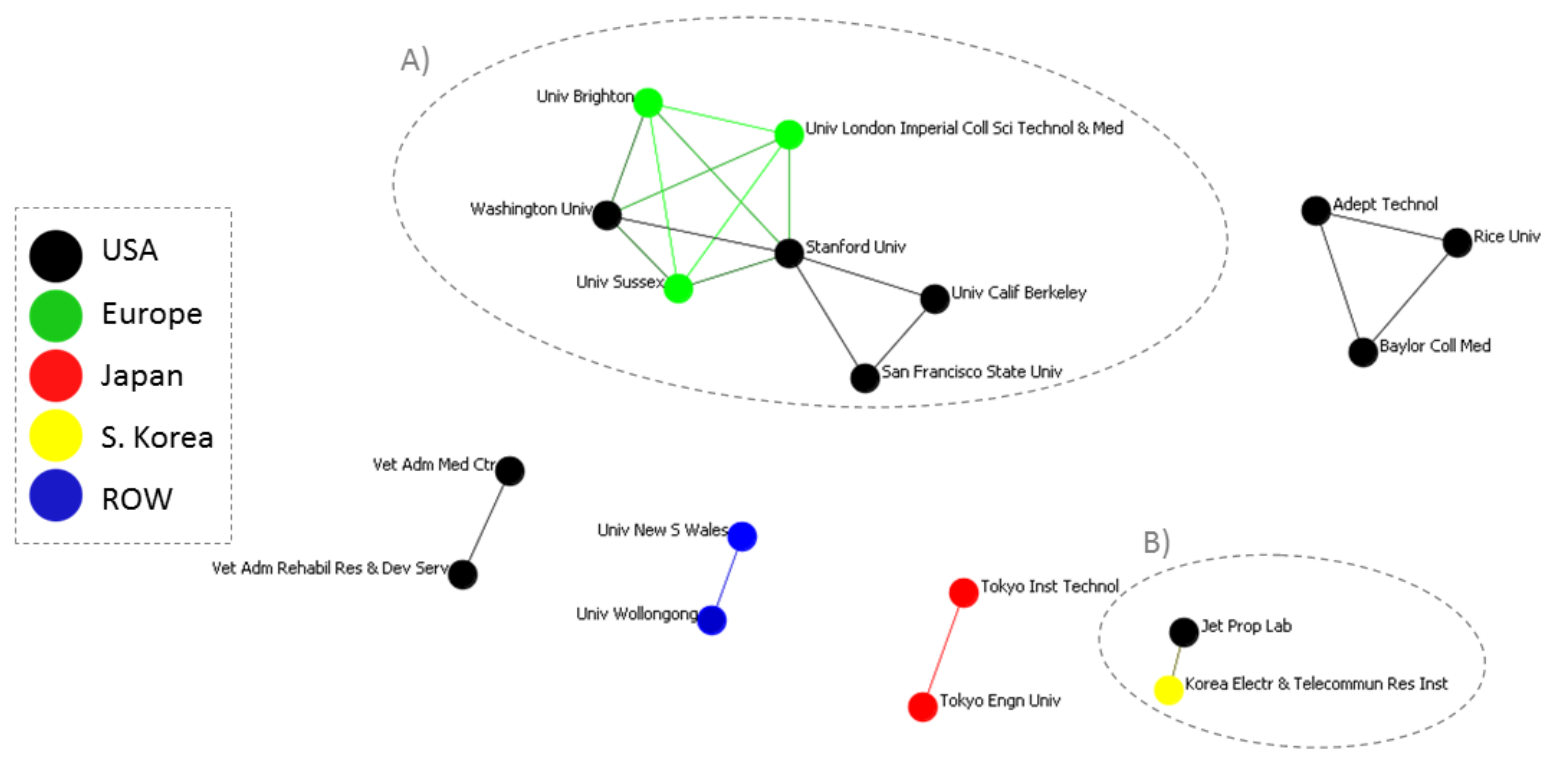

Figure 2: Collaboration networks (1983 - 1994)

\footnotetext{
${ }^{8}$ The relative low number of patent applications in 2009 can be explained because it takes 18 months until an application is disclosed to the public. Considering that the latest data was entered into the PATSTAT database end of July 2010, the amount of applications after January 2009 (July 2010 minus 18 months) is not necessarily complete. Using the values from 1980 to 2008 to extrapolate the date yields 57 annual patent applications for 2009, instead of 21 .
} 


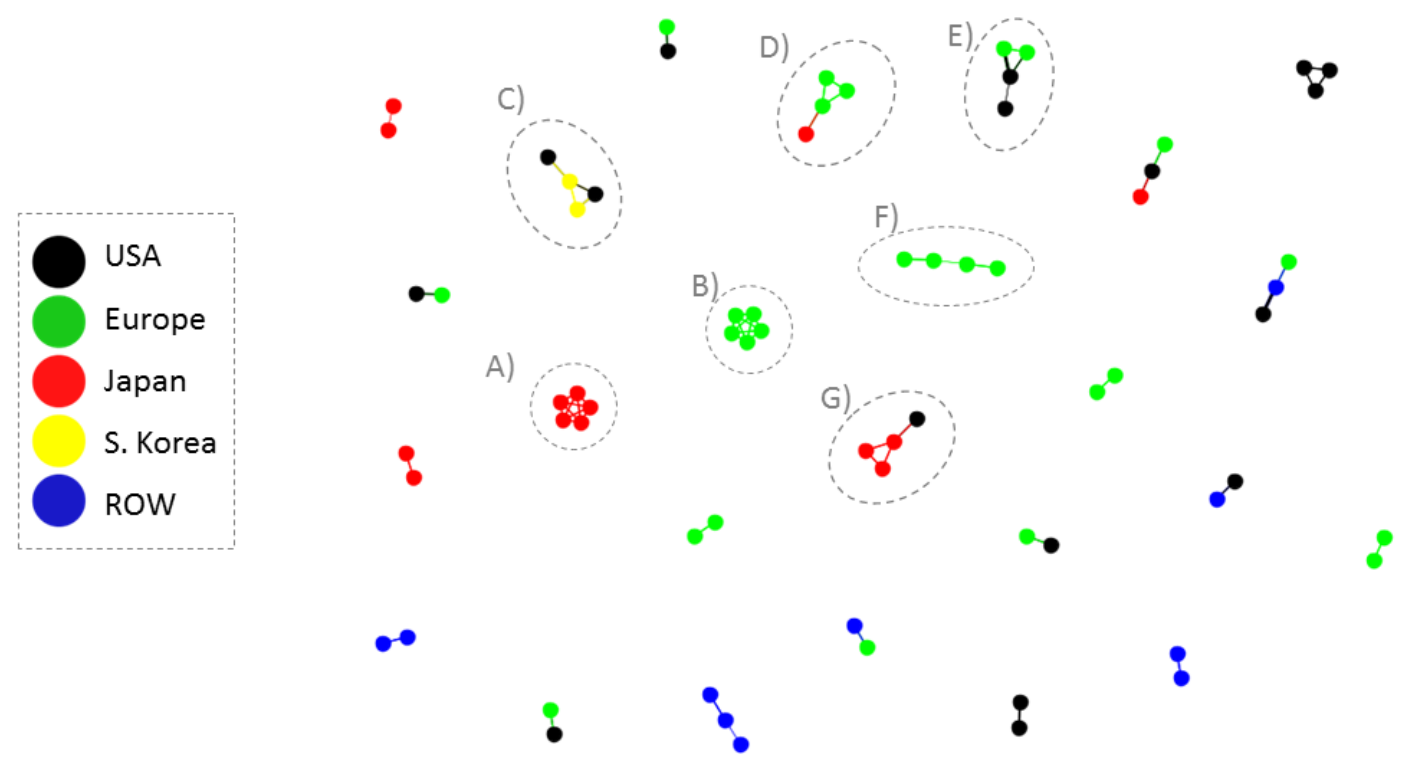

Figure 3: Collaboration networks (1995 - 1999)

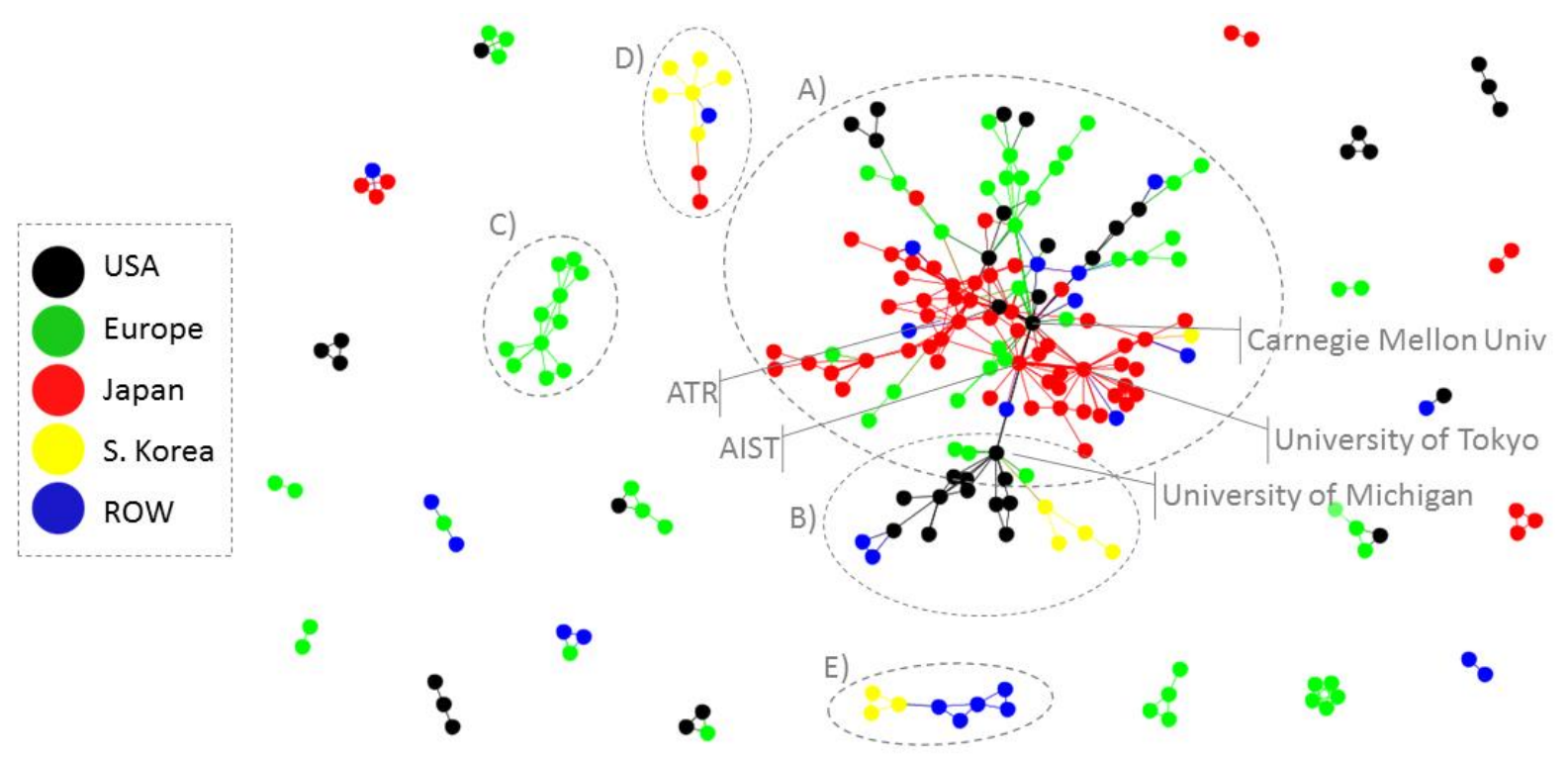

Figure 4: Collaboration networks with more than three partners (2000 - 2004) 


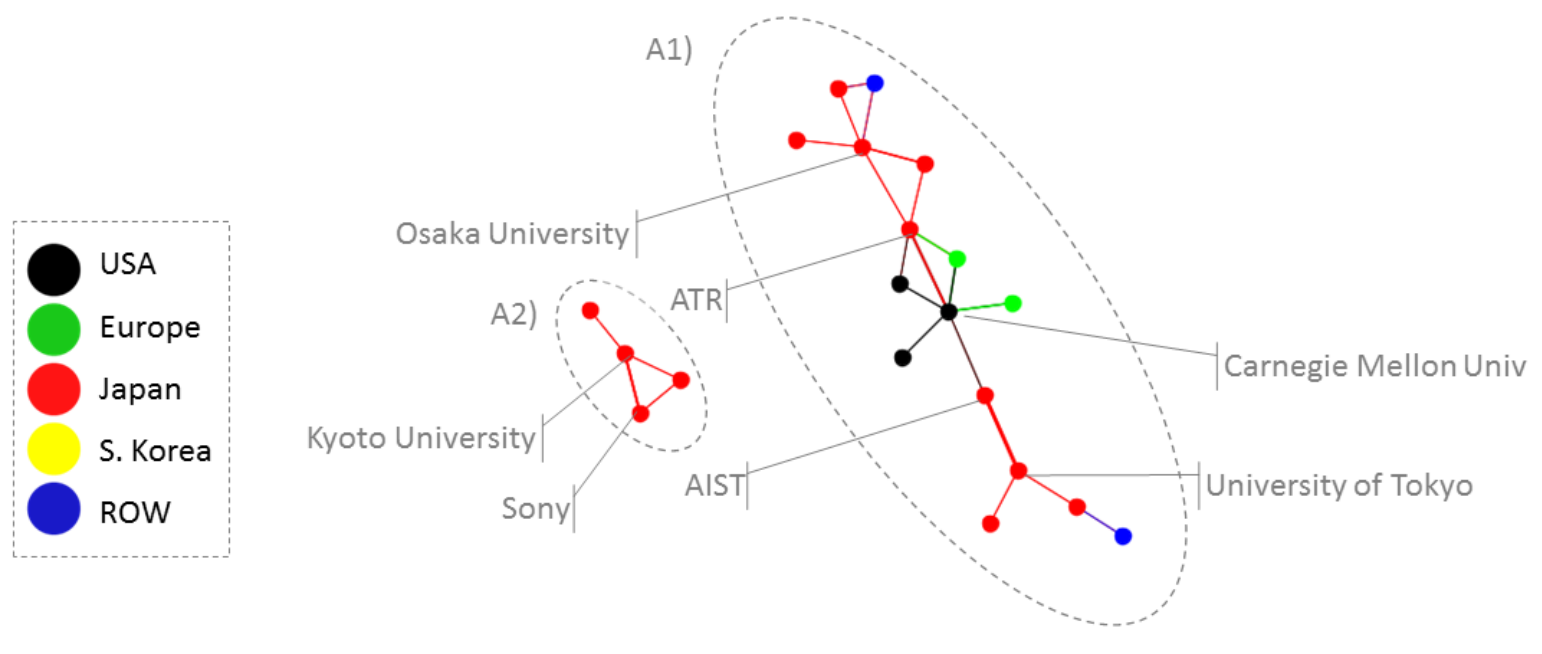

Figure 5: Collaboration sub-networks - more than one joint publication (2000 - 2004)

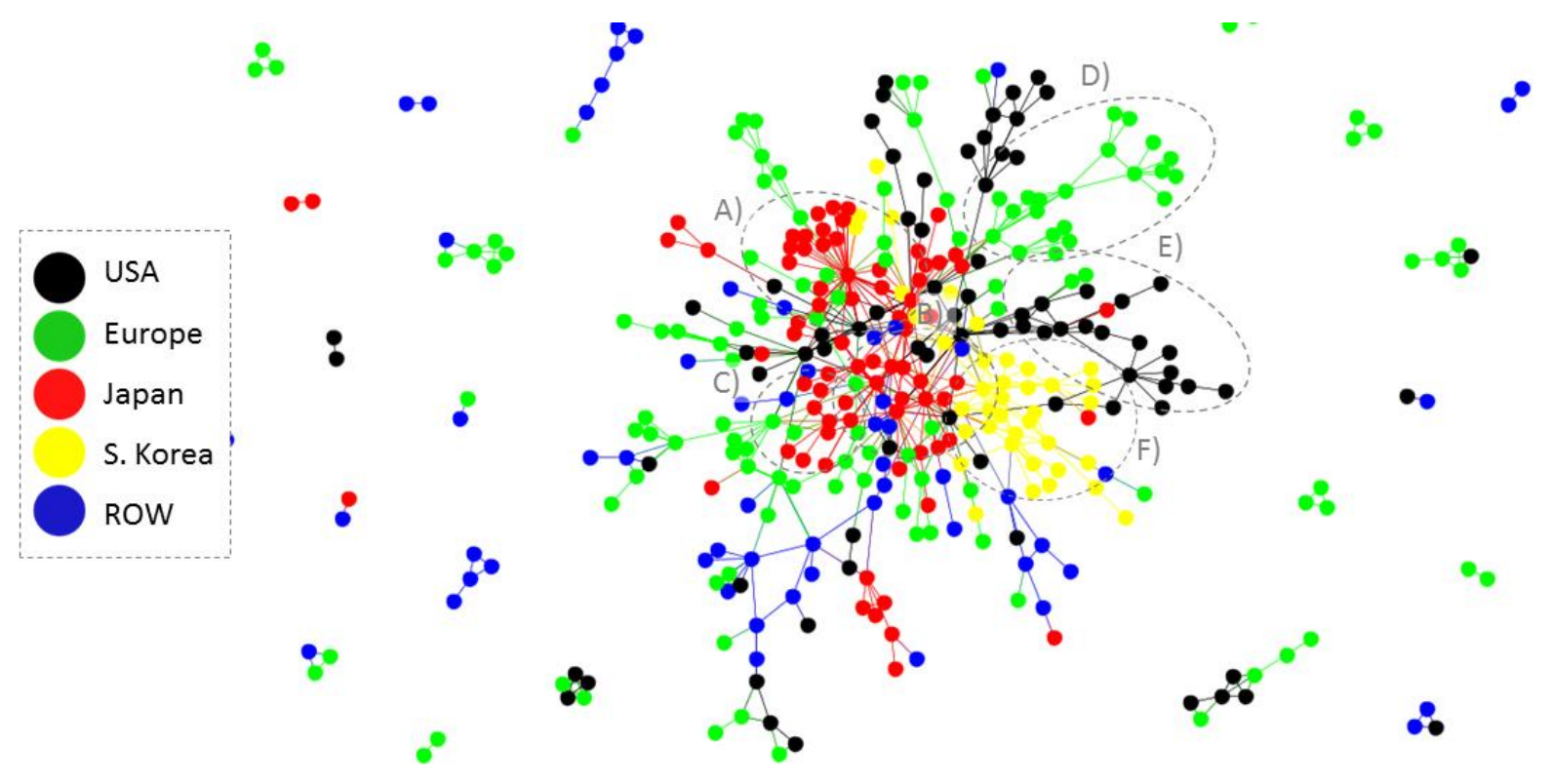

Figure 6: Collaboration networks with more than three partners (2005 - 2009) 


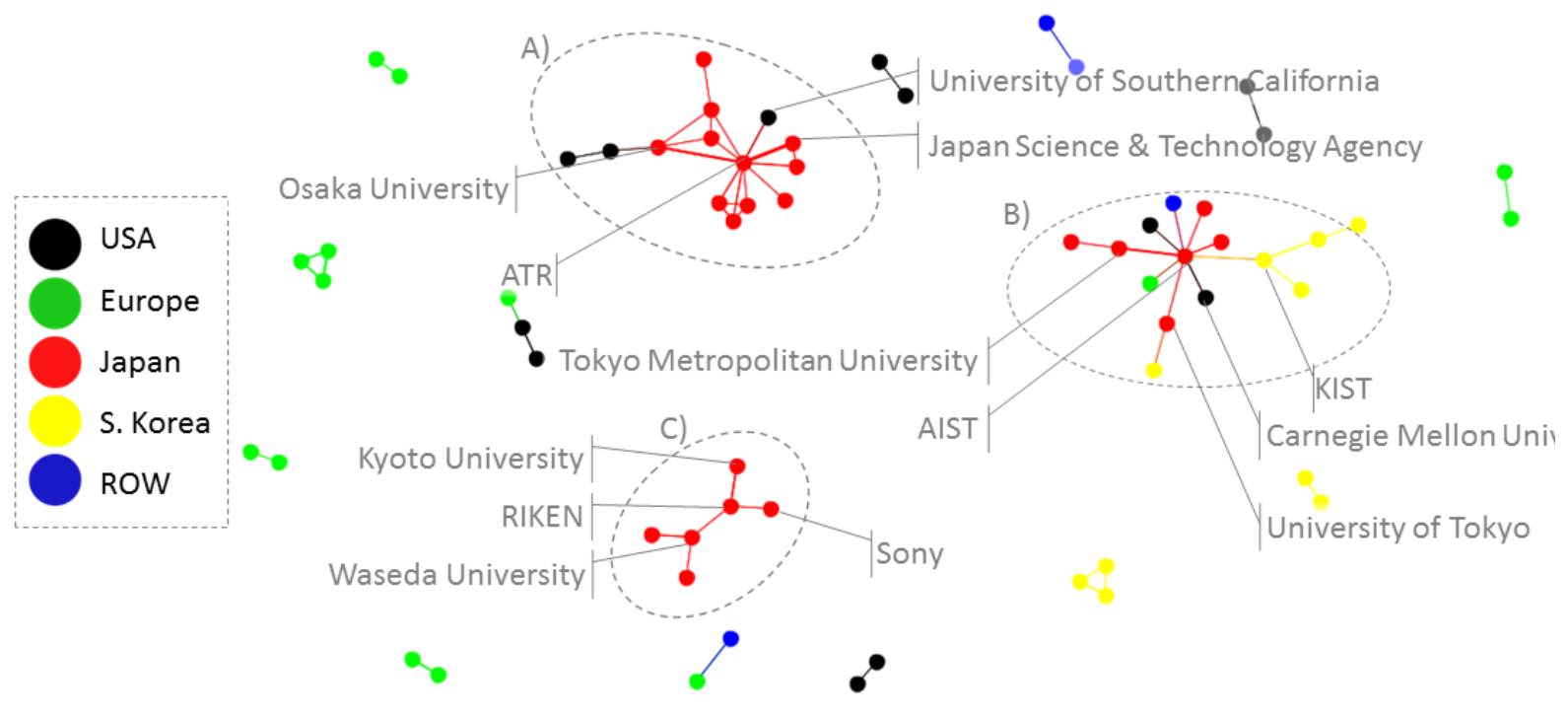

Figure 7: Collaboration network (2005 - 2009) - partners with more than one joint publication

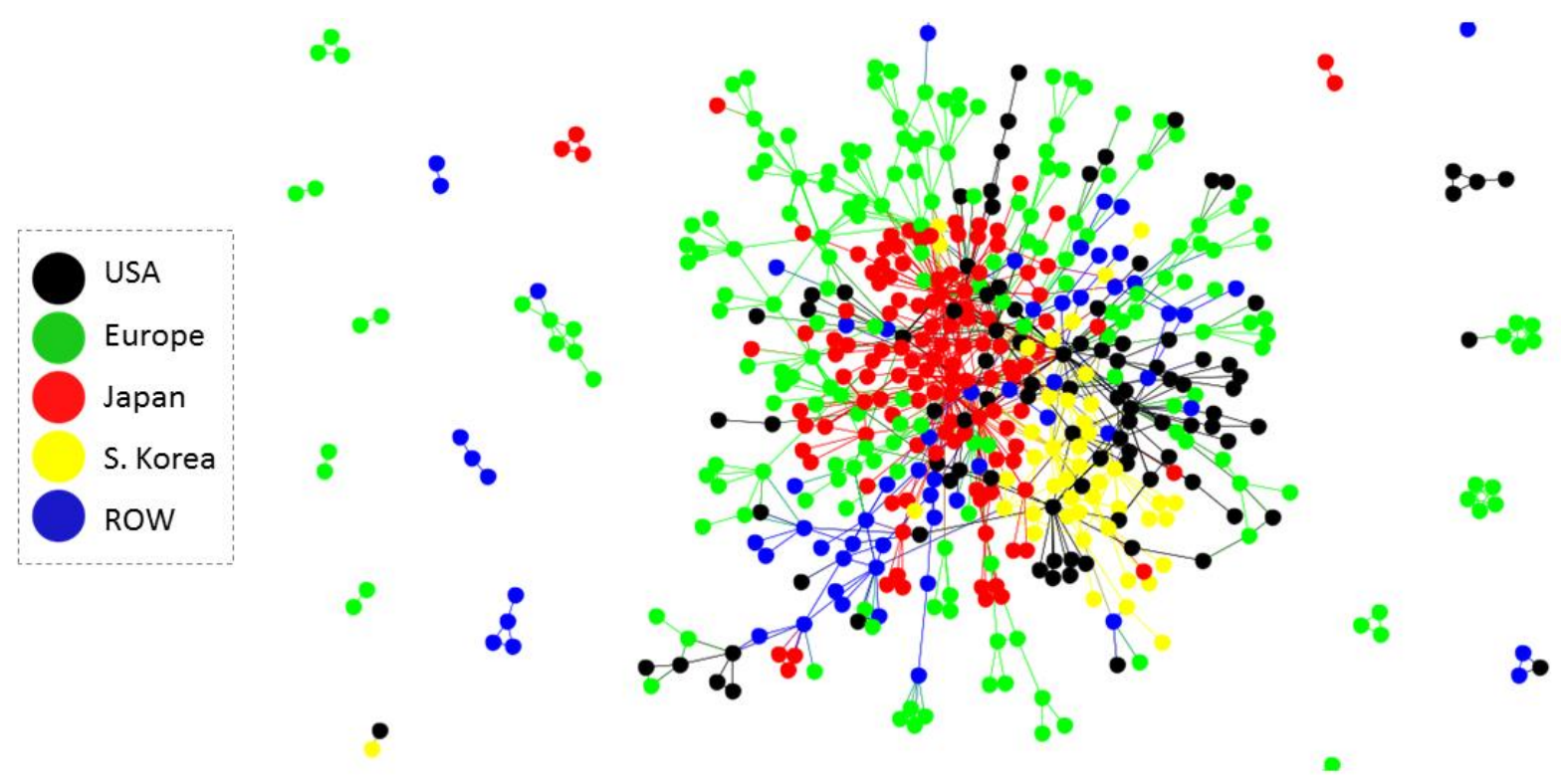

Figure 8: Overall collaboration networks with more than three partners $(1983-2009)$ 


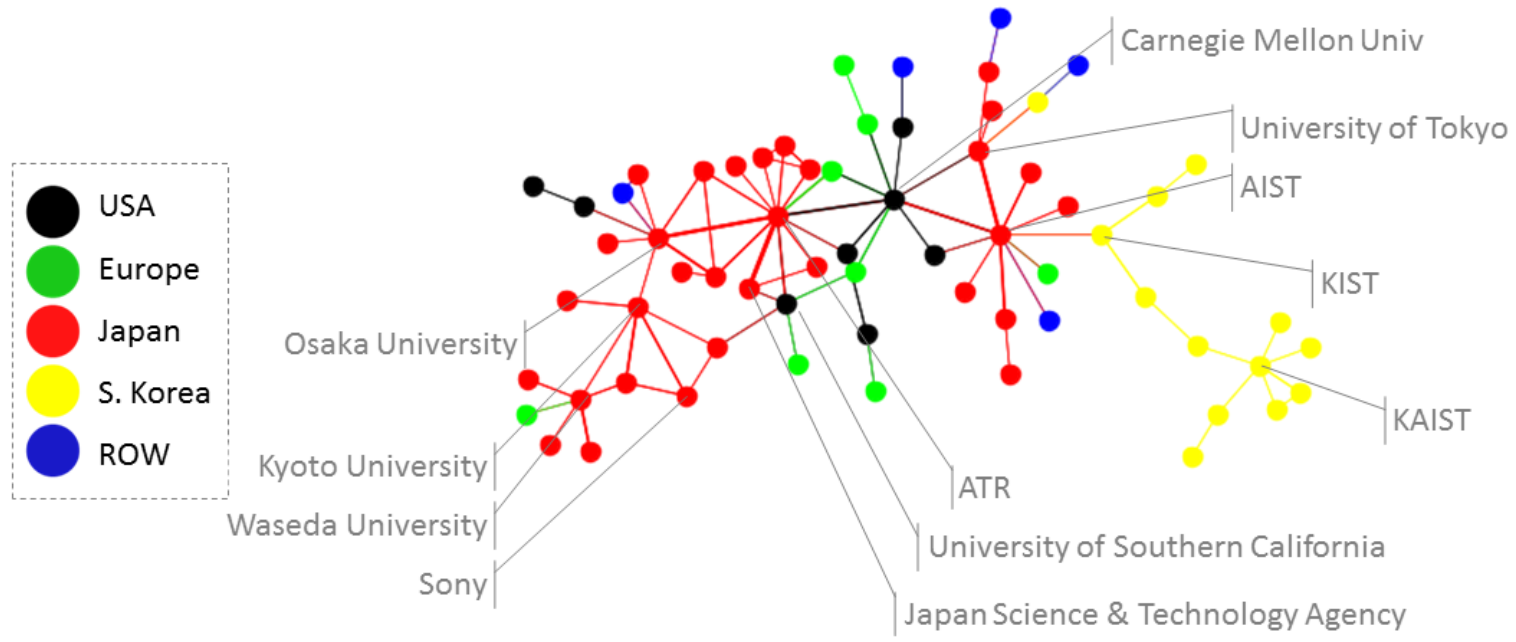

Figure 9: Overall collaboration network (1983 - 2009) - more than one joint publication 


\section{TABLES}

Table 1: Keywords for data collection search strategy of patents and publications

\begin{tabular}{llll}
\hline Positive-list 1 & Positive-list 2 & Negative-list & \\
\hline robot & health & industrial & surgical \\
robotics & care & automotive & anesthesia \\
& personal & construction & DNA \\
& partner & soccer & minimally invasive \\
humanoid & kids & endoscopy \\
& service & children & cancer \\
& companion & surgery & stroke \\
human-robot-interaction & & \\
& medical & & \\
& support & & \\
& assistant & & \\
& & & \\
\end{tabular}

Table 2: Geographical distribution (top-5 countries) of patenting and publishing activity (1974 - 2009)

\begin{tabular}{|c|c|c|c|c|c|c|c|c|c|c|c|c|}
\hline \multirow[b]{2}{*}{ Country } & \multicolumn{6}{|c|}{ Patent applications } & \multicolumn{6}{|c|}{ Scientific publications } \\
\hline & -1994 & $\begin{array}{l}1995- \\
1999\end{array}$ & $\begin{array}{l}2000- \\
2004\end{array}$ & $\begin{array}{l}2005- \\
2009\end{array}$ & Sum & $\begin{array}{c}\% \\
\text { total }\end{array}$ & $\begin{array}{l}1974- \\
1994\end{array}$ & $\begin{array}{l}1995- \\
1999\end{array}$ & $\begin{array}{l}2000- \\
2004\end{array}$ & $\begin{array}{l}2005- \\
2009\end{array}$ & Sum & $\begin{array}{c}\% \\
\text { total }\end{array}$ \\
\hline Japan & 77 & 72 & 165 & 87 & 401 & $71 \%$ & 8 & 31 & 126 & 176 & 341 & $22 \%$ \\
\hline China & - & - & 8 & 56 & 64 & $11 \%$ & - & 1 & 9 & 43 & 53 & $3 \%$ \\
\hline South Korea & - & 1 & 10 & 39 & 50 & $9 \%$ & 3 & 4 & 24 & 97 & 128 & $8 \%$ \\
\hline USA & 8 & 1 & 6 & 7 & 22 & $4 \%$ & 21 & 44 & 87 & 158 & 310 & $20 \%$ \\
\hline \multirow{2}{*}{$\begin{array}{l}\text { Germany } \\
\text { Other }\end{array}$} & 2 & - & 1 & 8 & 11 & $2 \%$ & 3 & 28 & 38 & 53 & 122 & $8 \%$ \\
\hline & & & & & 16 & $3 \%$ & & & & & 954 & $63 \%$ \\
\hline Total & & & & & 564 & & & & & & 1525 & \\
\hline
\end{tabular}


Table 3: Top 10 ranked organizations for overall patent (left) and publishing activity (right)

\begin{tabular}{|c|c|c|c|c|c|c|c|c|c|}
\hline Rank & Organization & $\begin{array}{l}\text { Pat. } \\
\text { appl. }\end{array}$ & $\begin{array}{l}\% \\
\text { total }\end{array}$ & $\begin{array}{l}\text { Cum. \% } \\
\text { total }\end{array}$ & Rank & Organization & $\begin{array}{l}\text { Sci. } \\
\text { Publ. }\end{array}$ & $\begin{array}{l}\% \\
\text { total }\end{array}$ & $\begin{array}{l}\text { Cum. \% } \\
\text { total }\end{array}$ \\
\hline 1 & Sony Corp (JP) & 28 & $5 \%$ & $5 \%$ & 1 & Univ. of Tokyo (JP) & 60 & $4 \%$ & $4 \%$ \\
\hline 2 & Honda Motor Co. (JP) & 25 & $4 \%$ & $9 \%$ & 2 & AIST (JP) & 45 & $3 \%$ & $7 \%$ \\
\hline 3 & Toshiba Corp (JP) & 22 & $4 \%$ & $13 \%$ & 3 & KAIST (KR) & 44 & $3 \%$ & $10 \%$ \\
\hline 4 & $\begin{array}{l}\text { Mitsubishi Heavy Ind } \\
\text { Ltd (JP) }\end{array}$ & 18 & $3 \%$ & $16 \%$ & 4 & $\begin{array}{l}\text { Carnegie Mellon } \\
\text { Univ. (US) }\end{array}$ & 42 & $3 \%$ & $13 \%$ \\
\hline 5 & Toyota Motor Corp (JP) & 17 & $3 \%$ & $20 \%$ & 4 & ATR (JP) & 42 & $3 \%$ & $15 \%$ \\
\hline 6 & Fujitsu Ltd (JP) & 14 & $2 \%$ & $22 \%$ & 5 & MIT (US) & 40 & $3 \%$ & $18 \%$ \\
\hline 6 & Hitachi Ltd (JP) & 14 & $2 \%$ & $24 \%$ & 6 & Osaka Univ. (JP) & 32 & $2 \%$ & $20 \%$ \\
\hline 6 & $\begin{array}{l}\text { Matsushita Electric Ind. } \\
\text { Co Ltd (JP) }\end{array}$ & 14 & $2 \%$ & $27 \%$ & 7 & Waseda Univ. (JP) & 26 & $2 \%$ & $22 \%$ \\
\hline 7 & $\begin{array}{l}\text { Nippon Telegr. \& } \\
\text { Teleph. Corp. (JP) }\end{array}$ & 12 & $2 \%$ & $29 \%$ & 8 & $\begin{array}{l}\text { Korea Inst. S\&T } \\
\text { (KR) }\end{array}$ & 25 & $2 \%$ & $23 \%$ \\
\hline 7 & $\begin{array}{l}\text { Samsung Electronics } \\
\text { Co. (KR) }\end{array}$ & 12 & $2 \%$ & $31 \%$ & 9 & $\begin{array}{l}\text { Univ. Karlsruhe } \\
\text { (DE) }\end{array}$ & 24 & $2 \%$ & $25 \%$ \\
\hline & Other & 388 & & & & Other & 1145 & & \\
\hline & Total & 564 & & & & Total & 1525 & & \\
\hline
\end{tabular}

Table 4: Top 10 ranked organizations for overall patent (left) and publishing activity (right)

\begin{tabular}{|c|c|c|c|c|c|c|c|}
\hline Rank & Organization & $\begin{array}{l}\text { Cum. } \\
\text { cit. p.a. }\end{array}$ & $\begin{array}{l}\text { Num. of } \\
\text { citations }\end{array}$ & Rank & Organization & $\begin{array}{l}\text { Cum. } \\
\text { cit. p.a. }\end{array}$ & $\begin{array}{l}\text { Num. of } \\
\text { citations }\end{array}$ \\
\hline 1 & $\begin{array}{l}\text { Carnegie Mellon } \\
\text { University (US) }\end{array}$ & 150,5 & 42 & 6 & $\begin{array}{l}\text { University of } \\
\text { Michigan (US) }\end{array}$ & 83,9 & 17 \\
\hline 2 & ATR (JP) & 101,6 & 42 & 7 & $\begin{array}{l}\text { University of Tokyo } \\
\text { (JP) }\end{array}$ & 82,3 & 60 \\
\hline 3 & MIT (US) & 97,6 & 40 & 8 & $\begin{array}{l}\text { University of } \\
\text { Southern California } \\
\text { (US) }\end{array}$ & 68,5 & 19 \\
\hline 4 & AIST (JP) & 96,5 & 45 & 9 & Osaka University (JP) & 57,0 & 32 \\
\hline 5 & $\begin{array}{l}\text { Ecole Polytechnique } \\
\text { (FR) }\end{array}$ & 92,9 & 16 & 10 & KAIST (SK) & 55,5 & 44 \\
\hline
\end{tabular}


Table 5: Top 10 ranked organizations measured by cumulative annual citations of patent applications

\begin{tabular}{|c|c|c|c|c|c|c|c|}
\hline Rank & Organization & $\begin{array}{l}\text { Cum. cit. } \\
\text { p.a. }\end{array}$ & $\begin{array}{l}\text { Num. of } \\
\text { citations }\end{array}$ & Rank & Organization & $\begin{array}{l}\text { Cum. cit. } \\
\text { p.a. }\end{array}$ & $\begin{array}{l}\text { Num. of } \\
\text { citations }\end{array}$ \\
\hline 1 & Sony Corp (JP) & 5,84 & 56 & 6 & $\begin{array}{l}\text { Gmf Robotics } \\
\text { Corporation }\end{array}$ & 1,30 & 31 \\
\hline 2 & $\begin{array}{l}\text { Honda Motor Co. } \\
\text { (JP) }\end{array}$ & 3,36 & 43 & 7 & $\begin{array}{l}\text { Intouch Health } \\
\text { Inc. }\end{array}$ & 3,63 & 29 \\
\hline 3 & Wes-Tech, Inc. (US) & 1,82 & 40 & 8 & $\begin{array}{l}\text { Irobot } \\
\text { Corporation (US) }\end{array}$ & 6,50 & 29 \\
\hline 4 & $\begin{array}{l}\text { Deutsche } \\
\text { Forschungsanstalt } \\
\text { Für Luft-Und } \\
\text { Raumfahrt E.V. (DE) }\end{array}$ & 2,38 & 38 & 9 & $\begin{array}{l}\text { Megamation Inc. } \\
\text { (US) }\end{array}$ & 1,38 & 29 \\
\hline 5 & $\begin{array}{l}\text { B.A.T. } \\
\text { Cigarettenfabriken } \\
\text { Gmbh (DE) }\end{array}$ & 1,39 & 32 & 10 & $\begin{array}{l}\text { Jardine } \\
\text { Industries, Inc. } \\
\text { (US) }\end{array}$ & 0,5 & 18 \\
\hline
\end{tabular}

Table 6: Top 10 ranked individuals for overall patent (left) and publishing activity (right)

\begin{tabular}{|c|c|c|c|c|c|c|c|}
\hline Rank & Individual & $\begin{array}{l}\text { Organization - } \\
\text { country }\end{array}$ & $\begin{array}{l}\text { pat. } \\
\text { appl. }\end{array}$ & Rank & Individual & $\begin{array}{l}\text { Organization - } \\
\text { country }\end{array}$ & $\begin{array}{l}\text { sci. } \\
\text { publ. }\end{array}$ \\
\hline 1 & Ryota, $\mathrm{H}$. & Mitsubishi (JP) & 9 & 1 & Breazeal, C. & MIT (US) & 19 \\
\hline 2 & Ishiguro, $\mathrm{H}$. & Osaka Univ. (JP) & 8 & 1 & Takanishi, A. & Waseda Univ. (JP) & 19 \\
\hline 3 & Qiang, H. & $\begin{array}{l}\text { Beijing Inst Tech } \\
\text { (CN) }\end{array}$ & 7 & 2 & Kajita, S. & AIST (JP) & 17 \\
\hline 3 & Akishi, K. & Kubota Corp (JP) & 7 & 3 & Ishiguro, H. & Osaka Univ. (JP) & 16 \\
\hline 3 & Onishi, K. & Mitsubishi (JP) & 7 & 4 & Inaba, M. & Univ. Tokyo (JP) & 15 \\
\hline 3 & Yamaguchi, J. & Sony (JP) & 7 & 5 & Cheng, G. & ATR (JP) & 14 \\
\hline 4 & Gomi, H. & $\begin{array}{l}\text { Honda Motor Co } \\
\text { (JP) }\end{array}$ & 6 & 5 & Inoue, $\mathrm{H}$. & Univ. Tokyo (JP) & 14 \\
\hline 4 & Hiroaki, K. & Tech Co (JP) & 6 & 6 & Kagami, S. & AIST (JP) & 13 \\
\hline 4 & Miyashita, K. & ATR (JP) & 6 & 6 & Kanda, T. & ATR (JP) & 13 \\
\hline \multirow[t]{3}{*}{4} & Furuta, T. & Tech Co (JP) & 6 & 6 & Okuno, H.G. & Kyoto Univ. (JP) & 13 \\
\hline & Other & & 495 & & Rest & & 1372 \\
\hline & Total & & 564 & & Total & & 1525 \\
\hline
\end{tabular}


Table 7: Top 10 scientific publications ranked by annual citations

\begin{tabular}{|c|c|c|c|c|c|}
\hline Authors & Title & $\begin{array}{l}\text { Publ. } \\
\text { year }\end{array}$ & $\begin{array}{l}\text { Total } \\
\text { cit. }\end{array}$ & $\begin{array}{c}\text { Annual } \\
\text { cit. }\end{array}$ & $\begin{array}{l}\text { Authors affiliated } \\
\text { organizations }\end{array}$ \\
\hline $\begin{array}{l}\text { Fong, T; Nourbakhsh, I; } \\
\text { Dautenhahn, K }\end{array}$ & $\begin{array}{l}\text { A survey of socially } \\
\text { interactive robots }\end{array}$ & 2003 & 228 & 32,6 & $\begin{array}{l}\text { Carnegie Mellon Univ } \\
\text { (US), Ecole Polytech (FR), } \\
\text { Univ Hertfordshire (UK) }\end{array}$ \\
\hline $\begin{array}{l}\text { Huang, Q; Yokoi, K; } \\
\text { Kajita, S; Kaneko, K; Arai, } \\
\text { H; Koyachi, N; Tanie, K }\end{array}$ & $\begin{array}{l}\text { Planning walking patterns } \\
\text { for a biped robot }\end{array}$ & 2001 & 197 & 21,9 & $\begin{array}{l}\text { Beijing Inst Technol (CN), } \\
\text { AIST (JP) }\end{array}$ \\
\hline $\begin{array}{l}\text { Westervelt, ER; Grizzle, } \\
\text { JW; Koditschek, DE }\end{array}$ & $\begin{array}{l}\text { Hybrid zero dynamics of } \\
\text { planar biped walkers }\end{array}$ & 2003 & 111 & 15,9 & Univ Michigan (US) \\
\hline Breazeal, C & $\begin{array}{l}\text { Emotion and sociable } \\
\text { humanoid robots }\end{array}$ & 2003 & 103 & 14,7 & MIT (US) \\
\hline $\begin{array}{l}\text { Dorigo, M; Trianni, V; } \\
\text { Sahin, E; Gross, R; } \\
\text { Labella, TH; Baldassarre, } \\
\text { G; Nolfi, S; Deneubourg, } \\
\text { JL; Mondada, F; } \\
\text { Floreano, D; } \\
\text { Gambardella, LM }\end{array}$ & $\begin{array}{l}\text { Evolving self-organizing } \\
\text { behaviors for a swarm-bot }\end{array}$ & 2004 & 78 & 13,0 & $\begin{array}{l}\text { Free Univ Brussels (BE), } \\
\text { Middle E Tech Univ (TR), } \\
\text { CNR (IT), Ecole Polytech } \\
\text { (FR) }\end{array}$ \\
\hline $\begin{array}{l}\text { Calinon, S; Guenter, F; } \\
\text { Billard, A }\end{array}$ & $\begin{array}{l}\text { On learning, representing, } \\
\text { and generalizing a task in a } \\
\text { humanoid robot }\end{array}$ & 2007 & 38 & 12,7 & Ecole Polytech (FR) \\
\hline Goswami, A & $\begin{array}{l}\text { Postural stability of biped } \\
\text { robots and the foot- } \\
\text { rotation indicator (FRI) } \\
\text { point }\end{array}$ & 1999 & 138 & 12,5 & $\begin{array}{l}\text { University of } \\
\text { Pennsylvania (US) }\end{array}$ \\
\hline $\begin{array}{l}\text { Saxena, A; Driemeyer, J; } \\
\mathrm{Ng}, \mathrm{AY}\end{array}$ & $\begin{array}{l}\text { Robotic grasping of novel } \\
\text { objects using vision }\end{array}$ & 2008 & 25 & 12,5 & Stanford University (US) \\
\hline $\begin{array}{l}\text { Harbourne, RT; Stergiou, } \\
\text { N }\end{array}$ & $\begin{array}{l}\text { Movement Variability and } \\
\text { the Use of Nonlinear Tools: } \\
\text { Principles to Guide } \\
\text { Physical Therapist Practice }\end{array}$ & 2009 & 12 & 12,0 & $\begin{array}{l}\text { University of Nebraska } \\
\text { (US) }\end{array}$ \\
\hline $\begin{array}{l}\text { Nakanishi, J; Morimoto, } \\
\text { J; Endo, G; Cheng, G; } \\
\text { Schaal, S; Kawato, M }\end{array}$ & $\begin{array}{l}\text { Learning from } \\
\text { demonstration and } \\
\text { adaptation of biped } \\
\text { locomotion }\end{array}$ & 2004 & 67 & 11,2 & $\begin{array}{l}\text { ATR (JP), Japan Sci \& } \\
\text { Technol Agcy (JP), Sony } \\
\text { (JP), Univ So Calif (US) }\end{array}$ \\
\hline
\end{tabular}


Table 8: Top 10 patent applications ranked by annual citations

\begin{tabular}{|c|c|c|c|c|c|}
\hline Authors & Title & $\begin{array}{l}\text { Publ. } \\
\text { year }\end{array}$ & $\begin{array}{l}\text { Total } \\
\text { cit. }\end{array}$ & $\begin{array}{c}\text { Annual } \\
\text { cit. }\end{array}$ & $\begin{array}{c}\text { Authors affiliated } \\
\text { organizations }\end{array}$ \\
\hline $\begin{array}{l}\text { Steven Edward Butner, Charles S. } \\
\text { Jordan, Keith Phillip Laby, } \\
\text { Jonathan Southard, Yulun Wang }\end{array}$ & $\begin{array}{l}\text { Medical tele-robotic } \\
\text { system }\end{array}$ & 2002 & 29 & 4,1 & $\begin{array}{l}\text { Intouch Health } \\
\text { Inc. (US) }\end{array}$ \\
\hline $\begin{array}{l}\text { Clive Bolton, Tony L. Campbell, } \\
\text { Matthew Cross, John Goetsch, } \\
\text { Amanda Gruber, Tim Bickmore, } \\
\text { Ken Singlair, Clara Vu, Lorin } \\
\text { Wilde, Pace Williston }\end{array}$ & $\begin{array}{l}\text { Companion robot for } \\
\text { personal interaction }\end{array}$ & 2006 & 9 & 3,0 & $\begin{array}{l}\text { Irobot } \\
\text { Corporation (US) }\end{array}$ \\
\hline $\begin{array}{l}\text { Clive Bolton, Tony L. Campbell, } \\
\text { Matthew Cross, John Goetsch, } \\
\text { Amanda Gruber, Tim Bickmore, } \\
\text { Ken Singlair, Clara Vu, Lorin } \\
\text { Wilde, Pace Williston }\end{array}$ & $\begin{array}{l}\text { Companion robot for } \\
\text { personal interaction }\end{array}$ & 2006 & 9 & 3,0 & $\begin{array}{l}\text { Irobot } \\
\text { Corporation (US) }\end{array}$ \\
\hline Jürgen Guldner & $\begin{array}{l}\text { Autonomous } \\
\text { navigation system for } \\
\text { mobile robot or } \\
\text { manipulator }\end{array}$ & 1994 & 38 & 2,5 & $\begin{array}{l}\text { Deutsche } \\
\text { Forschungsanstalt } \\
\text { Für Luft-Und } \\
\text { Raumfahrt E.V. } \\
\text { (DE) }\end{array}$ \\
\hline $\begin{array}{l}\text { Jinichi Yamaguchi, Tatsuzo } \\
\text { Ishida, Yoshihiro Kuroki, Yuichi } \\
\text { Hattori }\end{array}$ & $\begin{array}{l}\text { Robot and joint } \\
\text { device for the same }\end{array}$ & 1999 & 24 & 2,4 & Sony Corp (JP) \\
\hline $\begin{array}{l}\text { Clive Bolton, Tony L. Campbell, } \\
\text { Matthew Cross, John Goetsch, } \\
\text { Amanda Gruber, Tim Bickmore, } \\
\text { Ken Singlair, Clara Vu, Lorin } \\
\text { Wilde, Pace Williston }\end{array}$ & $\begin{array}{l}\text { Companion robot for } \\
\text { personal interaction }\end{array}$ & 2005 & 9 & 2,3 & $\begin{array}{l}\text { Irobot } \\
\text { Corporation (US) }\end{array}$ \\
\hline $\begin{array}{l}\text { Robert Weskamp, M. Richard } \\
\text { Tennerstedt }\end{array}$ & $\begin{array}{l}\text { Quick changecoupling } \\
\text { system for robotic } \\
\text { attachments }\end{array}$ & 1988 & 40 & 1,9 & $\begin{array}{l}\text { Wes-Tech, Inc. } \\
\text { (US) }\end{array}$ \\
\hline $\begin{array}{l}\text { Uwe Gerstmann, Heinz Krappitz, } \\
\text { Johannes Wolfrum }\end{array}$ & $\begin{array}{l}\text { Vorrichtung Zum } \\
\text { Abheben Mindestens } \\
\text { Eines Material- } \\
\text { Stapels }\end{array}$ & 1987 & 32 & 1,5 & $\begin{array}{l}\text { B.A.T. } \\
\text { Cigarettenfabriken } \\
\text { Gmbh (DE) }\end{array}$ \\
\hline $\begin{array}{l}\text { Brian D. Hoffman, Steven H. } \\
\text { Pollack }\end{array}$ & $\begin{array}{l}\text { Method And } \\
\text { Apparatus For Anti- } \\
\text { Collision And Collision } \\
\text { Protection For } \\
\text { Multiple Robot } \\
\text { System }\end{array}$ & 1989 & 29 & 1,5 & $\begin{array}{l}\text { Megamation Inc. } \\
\text { (US) }\end{array}$ \\
\hline Thomas Bayer & $\begin{array}{l}\text { Method for color } \\
\text { measuring of print } \\
\text { substrate ... }\end{array}$ & 2000 & 11 & 1,2 & $\begin{array}{l}\text { Wittenstein Gmbh } \\
\text { \& Co. } \mathrm{Kg}(\mathrm{DE})\end{array}$ \\
\hline
\end{tabular}


Table 9: Development of the collaborative patenting and publishing activity

\begin{tabular}{lcc}
\hline Period & Number of patent cooperations & Number of publication cooperations \\
\hline-1994 & 3 & 7 \\
$1995-1999$ & 3 & 36 \\
$2000-2004$ & 12 & 215 \\
$2005-2009$ & 5 & 447 \\
\hline Total & 23 & 706 \\
\hline
\end{tabular}

Table 10: Overview of collaborative developed patent applications

\begin{tabular}{|c|c|c|}
\hline Title & Appl. year & Partner \\
\hline Joint Structure Of Robot & 1987 & Daikin Ind Ltd, University of Tokyo \\
\hline Robot Hand & 1994 & Meidensha Corp, Tokai Rubber Ind Ltd \\
\hline \multirow[t]{2}{*}{ Method For Transmitting Graphic Information } & 1994 & Nippon Steel Corp, Nittetsu Elex Co Ltd \\
\hline & & Hakusan Seisakusho, Nippon Telegr \& \\
\hline \multirow[t]{3}{*}{ Compliance Mechanism Of Robot Hand } & 1996 & \\
\hline & & Teleph Corp \\
\hline & & Agency Of Industrial Science \& Technology, \\
\hline \multirow[t]{2}{*}{ Remote Control Support Device Of Robot } & 1996 & \\
\hline & & Toshiba Corp \\
\hline Robot And Joint Device For The Same & 1999 & Sony Corp, Yamaguchi Robotics Institute \\
\hline \multicolumn{3}{|l|}{ Leg Type Mobile Robot, And Leg Structure And Mobile } \\
\hline & 2000 & Sony Corp, Yamaguchi Robotics Institute \\
\hline \multicolumn{3}{|l|}{ Leg Unit For The Same } \\
\hline \multirow{4}{*}{ Service Robot And Service System Using It } & & Jce Kk ${ }^{9}$, Piisueito Kk, Tohoku Techno Arch \\
\hline & 2000 & \\
\hline & & Co Ltd, Yamatake Corp \\
\hline & & Japan Science And Technology \\
\hline \multirow[t]{2}{*}{ Thin-Film Tactile Sensor } & 2000 & Corporation, Research Institute Electric \\
\hline & & Magnetic Alloys \\
\hline \multirow[t]{2}{*}{ Offset Rotational Joint Unit With Rotation Correction } & & National Aerospace Laboratory Of Japan, \\
\hline & 2001 & \\
\hline \multirow[t]{2}{*}{ Mechanism } & & Koonan Engineering Kk \\
\hline & & Kawada Kogyo Kk, National Institute Of \\
\hline \multirow[t]{2}{*}{ Additional Support Structure For Robot } & 2002 & \\
\hline & & Advanced Industrial \& Technology \\
\hline Motion Controlling Apparatus And Motion Controlling & 2002 & Sony Corp, Yamaguchi Robotics Institute \\
\hline
\end{tabular}

${ }^{9} \mathrm{Kk}=$ Kabushiki kaisha, Japanese for "stock company" 


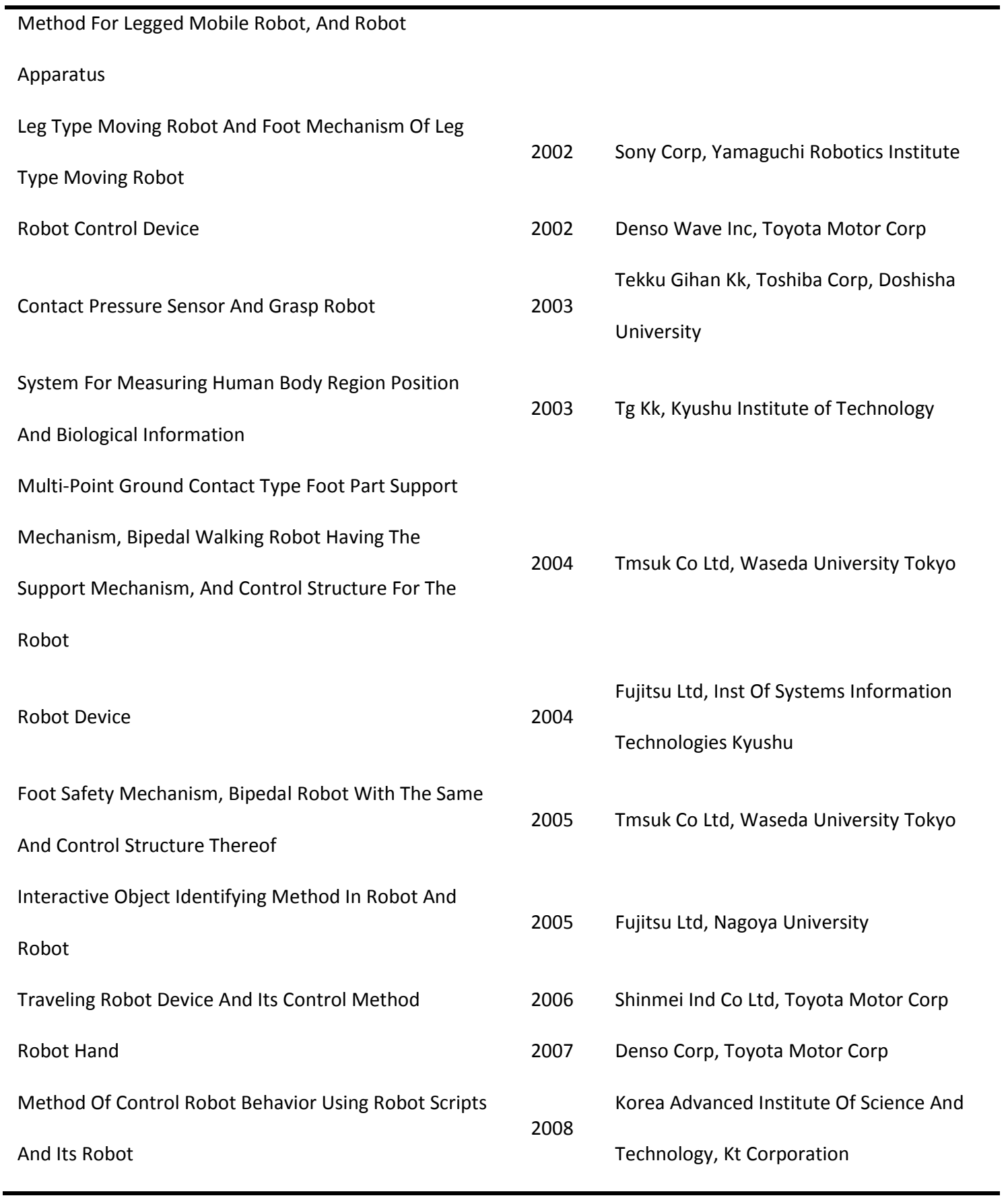


Table 11: Network measures (1995 - 1999)

\begin{tabular}{|c|c|c|c|c|c|c|c|}
\hline \multicolumn{6}{|c|}{ Overall Density } & \multicolumn{2}{|l|}{0,024} \\
\hline \multicolumn{6}{|c|}{ Total number of organizations } & 164 & \\
\hline \multicolumn{6}{|c|}{$\begin{array}{l}\text { Number of collaborating organizations with at least one co-authorship (Number of } \\
\text { Nodes) }\end{array}$} & 70 & \\
\hline \multicolumn{6}{|c|}{ Percentage of collaborating organizations with at least one co-authorship } & $43 \%$ & \\
\hline \multicolumn{8}{|c|}{ Top 11 Degree Centrality } \\
\hline \multicolumn{6}{|c|}{ Brunel University (UK) } & \multicolumn{2}{|l|}{0,029} \\
\hline \multicolumn{6}{|c|}{ Carnegie Mellon University (US) } & \multicolumn{2}{|l|}{0,029} \\
\hline \multicolumn{6}{|c|}{ Hokkaido University (JP) } & \multicolumn{2}{|l|}{0,029} \\
\hline \multicolumn{6}{|c|}{ Imperial Cancer Research Fund (UK) } & \multicolumn{2}{|l|}{0,029} \\
\hline \multicolumn{6}{|c|}{ Integral Solutions Ltd (UK) } & \multicolumn{2}{|l|}{0,029} \\
\hline \multicolumn{6}{|c|}{ Kochi Medical School (JP) } & \multicolumn{2}{|l|}{0,029} \\
\hline \multicolumn{6}{|c|}{ Kochi University of Technology (JP) } & \multicolumn{2}{|l|}{0,029} \\
\hline \multicolumn{6}{|c|}{ Matsushita Elect Works Ltd (JP) } & \multicolumn{2}{|l|}{0,029} \\
\hline \multicolumn{6}{|c|}{ Nippon Medical School (JP) } & \multicolumn{2}{|l|}{0,029} \\
\hline \multicolumn{6}{|c|}{ University of London, Imperial College (UK) } & \multicolumn{2}{|l|}{0,029} \\
\hline \multicolumn{6}{|c|}{ University of London, Queen Mary \& Westfield College (UK) } & \multicolumn{2}{|l|}{0,029} \\
\hline \multicolumn{8}{|c|}{ Number of organizations per region and type } \\
\hline USA & Japan & S. Korea & Europe & ROW & University & & Companies \\
\hline $17(24 \%)$ & $14(20 \%)$ & $2(3 \%)$ & $27(39 \%)$ & $10(14 \%)$ & $60(86 \%)$ & & $10(14 \%)$ \\
\hline
\end{tabular}

Table 12: Network measures (2000 - 2004)

\begin{tabular}{|c|c|c|c|c|c|c|}
\hline \multicolumn{6}{|c|}{ Overall Density } & 0,00928 \\
\hline \multicolumn{6}{|c|}{ Total number of organizations } & 443 \\
\hline \multicolumn{6}{|c|}{ Number of collaborating organizations with at least one co-authorship (Number of } & 285 \\
\hline \multicolumn{6}{|c|}{ Percentage of collaborating organizations with at least one co-authorship } & $46 \%$ \\
\hline \multicolumn{7}{|c|}{ Top 10 Degree Centrality } \\
\hline \multicolumn{6}{|c|}{ Carnegie Mellon University (US) } & 0.1092 \\
\hline \multicolumn{6}{|c|}{ University of Tokyo (JP) } & 0.0951 \\
\hline \multicolumn{6}{|c|}{ ATR (JP) } & 0.0810 \\
\hline \multicolumn{6}{|l|}{ AIST (JP) } & 0.0739 \\
\hline \multicolumn{6}{|c|}{ Osaka University (JP) } & 0.0704 \\
\hline \multicolumn{6}{|c|}{ Sony (JP) } & 0.0669 \\
\hline \multicolumn{6}{|c|}{ Kyoto University (JP) } & 0.0528 \\
\hline \multicolumn{6}{|c|}{ Tokyo Institute of Technology (JP) } & 0.0458 \\
\hline \multicolumn{6}{|c|}{ University Michigan (US) } & 0.0458 \\
\hline \multicolumn{6}{|c|}{ Japan Sci \& Technol Agency (JP) } & 0.0387 \\
\hline \multicolumn{7}{|c|}{ Number of organizations per region and type } \\
\hline USA & Japan & S. Korea & Europe & ROW & Universities & Companies \\
\hline 59 (21\%) & $80(28 \%)$ & 16 (6\%) & 89 (31\%) & 41 (14\%) & 231 (81\%) & 54 (19\%) \\
\hline
\end{tabular}


Table 13: Network measures (2005 - 2009)

\begin{tabular}{|c|c|c|c|c|c|c|}
\hline \multicolumn{6}{|c|}{ Overall Density } & 0,00519 \\
\hline \multicolumn{6}{|c|}{ Total number of organizations } & 661 \\
\hline \multicolumn{6}{|c|}{ Number of collaborating organizations with at least one co-authorship (Number of } & 542 \\
\hline \multicolumn{7}{|l|}{ Nodes) } \\
\hline \multicolumn{6}{|c|}{ Percentage of collaborating organizations with at least one co-authorship } & $82 \%$ \\
\hline \multicolumn{7}{|c|}{ Top 10 Degree Centrality } \\
\hline \multicolumn{6}{|l|}{ ATR (JP) } & 0.1165 \\
\hline \multicolumn{6}{|c|}{ AIST (JP) } & 0.0739 \\
\hline \multicolumn{6}{|c|}{ Osaka University (JP) } & 0.0536 \\
\hline \multicolumn{6}{|c|}{ KIST (SK) } & 0.0444 \\
\hline \multicolumn{6}{|c|}{ University Tokyo (JP) } & 0.0444 \\
\hline \multicolumn{6}{|c|}{ Japan Sci \& Technol Agcy (JP) } & 0.0388 \\
\hline \multicolumn{6}{|c|}{ Carnegie Mellon University (US) } & 0.0370 \\
\hline \multicolumn{6}{|c|}{ University of Southern California (US) } & 0.0333 \\
\hline \multicolumn{6}{|c|}{ Tokyo Metropolitan University (JP) } & 0.0314 \\
\hline \multicolumn{6}{|c|}{ Kyoto University (JP) } & 0.0296 \\
\hline \multicolumn{7}{|c|}{ Number of organizations per region and type } \\
\hline USA & Japan & S. Korea & Europe & ROW & Universities & Companies \\
\hline 117 (22\%) & $88(16 \%)$ & 51 (9\%) & 191 (35\%) & 95 (18\%) & 456 (84\%) & 86 (16\%) \\
\hline
\end{tabular}

Table 14: Overall Network measures (1983 - 2009)

\begin{tabular}{|c|c|c|c|c|c|c|}
\hline \multicolumn{6}{|c|}{ Overall Density } & 0,00386 \\
\hline \multicolumn{6}{|c|}{ Total number of organizations } & 957 \\
\hline \multicolumn{6}{|c|}{ Number of collaborating organizations with at least one co-authorship (Number of } & 756 \\
\hline \multicolumn{6}{|c|}{ Percentage of collaborating organizations with at least one co-authorship } & $79 \%$ \\
\hline \multicolumn{7}{|c|}{ Top 10 Degree Centrality } \\
\hline \multicolumn{6}{|c|}{ ATR (JP) } & 0.1086 \\
\hline \multicolumn{6}{|l|}{ AIST (JP) } & 0.0768 \\
\hline \multicolumn{6}{|c|}{ Carnegie Mellon University (US) } & 0.0662 \\
\hline \multicolumn{6}{|c|}{ University of Tokyo (JP) } & 0.0649 \\
\hline \multicolumn{6}{|c|}{ Osaka University (JP) } & 0.0649 \\
\hline \multicolumn{6}{|c|}{ Korea Inst Sci \& Technol (SK) } & 0.0397 \\
\hline \multicolumn{6}{|c|}{ Kyoto University (JP) } & 0.0397 \\
\hline \multicolumn{6}{|c|}{ University South California (US) } & 0.0384 \\
\hline \multicolumn{6}{|c|}{ Sony (JP) } & 0.0305 \\
\hline \multicolumn{6}{|c|}{ Japan Sci \& Technol Agcy (JP) } & 0.0291 \\
\hline \multicolumn{7}{|c|}{ Number of institutions per region and type } \\
\hline USA & Japan & S. Korea & Europe & ROW & Universities & Companies \\
\hline 167 (22\%) & $140(19 \%)$ & $56(7 \%)$ & $271(36 \%)$ & $122(16 \%)$ & 622 (82\%) & $134(18 \%)$ \\
\hline
\end{tabular}


Table 15: Network measures - Top 5 companies

\begin{tabular}{lll}
\hline \multicolumn{2}{c}{ Company name (nationality) } & Degree Centrality \\
\hline 1. & Sony (JP) & 0.0305 \\
2. & Samsung (KR) & 0.0132 \\
3. & Honda (JP) & 0.0119 \\
4. Matsushita (JP) & 0.0106 \\
5. LG Elect (KR) & 0.0066 \\
\hline
\end{tabular}

